\title{
Selective Engagement of Fc $\gamma$ RIV by a M2e-Specific Single Domain Antibody Construct Protects Against Influenza A Virus Infection
}

\author{
Dorien De Vlieger ${ }^{1,2,3}$, Katja Hoffmann ${ }^{4}$, Inge Van Molle ${ }^{5,6}$, Wim Nerinckx ${ }^{1,3}$, \\ Lien Van Hoecke ${ }^{1,2}$, Marlies Ballegeer ${ }^{1,2,3}$, Sarah Creytens ${ }^{1,2,3}$, Han Remaut ${ }^{5,6}$, \\ Hartmut Hengel ${ }^{4}$, Bert Schepens ${ }^{1,2 *}$ and Xavier Saelens ${ }^{1,2,3 *}$
}

${ }^{1}$ VIB-UGent Center for Medical Biotechnology, VIB, Ghent, Belgium, ${ }^{2}$ Department of Biomedical Molecular Biology, Ghent University, Ghent, Belgium, ${ }^{3}$ Department of Biochemistry and Microbiology, Ghent University, Ghent, Belgium, ${ }^{4}$ Institute of Virology, Medical Center, Faculty of Medicine, University of Freiburg, Freiburg, Germany, ${ }^{5}$ Structural Biology Brussels, Vrije Universiteit Brussel, Brussels, Belgium, ${ }^{6}$ VIB-VUB Center for Structural Biology, Brussels, Belgium

Lower respiratory tract infections, such as infections caused by influenza A viruses, are a constant threat for public health. Antivirals are indispensable to control disease caused by epidemic as well as pandemic influenza A. We developed a novel anti-influenza A virus approach based on an engineered single-domain antibody $(\mathrm{VHH})$ construct that can selectively recruit innate immune cells to the sites of virus replication. This protective construct comprises two VHHs. One VHH binds with nanomolar affinity to the conserved influenza A matrix protein 2 (M2) ectodomain (M2e). Co-crystal structure analysis revealed that the complementarity determining regions 2 and 3 of this $\mathrm{VHH}$ embrace M2e. The second selected VHH specifically binds to the mouse Fc $\gamma$ Receptor IV (FcyRIV) and was genetically fused to the M2e-specific $\mathrm{VHH}$, which resulted in a bi-specific $\mathrm{VHH}$ based construct that could be efficiently expressed in Pichia pastoris. In the presence of M2 expressing or influenza A virus-infected target cells, this single domain antibody construct selectively activated the mouse Fc $\gamma$ RIV. Moreover, intranasal delivery of this bispecific Fc $\gamma$ RIV-engaging $\mathrm{VHH}$ construct protected wild type but not $F_{C} \gamma R V^{-/-}$mice against challenge with an H3N2 influenza virus. These results provide proof of concept that $\mathrm{VHH}$ directed against a surface exposed viral antigen can be readily armed with effector functions that trigger protective antiviral activity beyond direct virus neutralization.

Keywords: influenza, matrix protein 2 ectodomain, single domain antibody, Fc $\gamma$ receptor, effector functions

\section{INTRODUCTION}

Influenza A virus infections are a major recurrent cause of seasonal respiratory tract infections. The best way to prevent influenza disease is considered to be vaccination. However due to the accumulation of point mutations in the viral hemagglutinin (HA) and neuraminidase (NA) genes, human influenza vaccines need to be reformulated and administered regularly based on the prediction of the circulating strains (1). The variable effectiveness and the long manufacturing timeline encourage the development of more broadly protective vaccines. Antivirals, such as oseltamivir and baloxavir marboxil, have been licensed for the prophylaxis and treatment of uncomplicated influenza, but the risk of selecting drug resistant viruses limits their widespread use $(2,3)$. 
The 23 amino acid residues long M2 ectodomain (M2e) is highly conserved among the different influenza A virus subtypes and thus represents an attractive target for broadly protective prophylactic vaccine strategies as well as for antibody-based antiviral biologicals [reviewed in Saelens (4)] $(4,5)$. Various studies using different vaccine formats have demonstrated that M2e-based vaccination can provide broad protection in animal models of influenza $\mathrm{A}$ and that this protection is antibody mediated (6-9). Next to vaccines, a therapeutic intervention with an intravenously administered recombinant human IgG1 monoclonal antibody directed against the M2 N-terminus was found to reduce the symptoms in human volunteers that had been infected with an H3N2 virus (10). Furthermore, this phase 2a trial showed that the antibody treatment was associated with a trend toward reduced viral shedding from the nasal mucosa, and no anti-M2e escape mutants could be detected. Finally, intravenous administration of engineered, so called bispecific $\mathrm{T}$ cell engagers that comprise a M2e-specific single chain variable fragment that is linked to a CD3E-specific single chain variable fragment, could protect mice against an otherwise lethal influenza A virus challenge (11).

$\mathrm{Fc}$ gamma receptor $(\mathrm{F} c \gamma \mathrm{R})$ interactions are essential for the protective activity of M2e-specific antibodies (12-14). Fc $\gamma$ Rs are type I membrane proteins that are expressed on different innate immune cells, including macrophages, neutrophils, natural killer cells and dendritic cells $(15,16)$. In mice, Fc $\gamma$ Rs are characterized by the presence of an immunoreceptor tyrosine-based activation motif (ITAM) in the cytoplasmic portion of the common $\gamma$ chain that is associated with the activating Fc $\gamma$ RI, Fc $\gamma$ RIII and Fc $\gamma$ RIV, or by an immunoreceptor tyrosine-based inhibition motif (ITIM) in the cytoplasmic portion of the inhibitory Fc $\gamma$ RIIb (17-19). These receptors differ in their affinities for the different IgG isotypes $(16,20)$. Previously, we have shown that protection by M2e-specific mouse IgG1 requires Fc $\gamma$ RIII while IgG2a isotypes can protect by any of the three activating Fc $\gamma$ Rs (13).

Since the reported discovery of heavy chain-only antibodies in camelids in 1993, recombinant single domain proteins comprising the variable domain of these antibodies (VHHs also known as Nanobodies ${ }^{\circledR}$ ) have been used in numerous therapeutic applications (21). In the context of viral infections, various virus-neutralizing VHHs have been described that can interfere with different steps in the viral life cycle (22). Due to their outstanding stability and solubility, as well as their small size $(\sim 15 \mathrm{kDa})$, ease of production and formatting flexibility, they are highly versatile building blocks for the development of new antivirals. Next to a direct antiviral effect, VHHs can also easily be formatted (e.g., by generating Fc fusions) to recruit host effector functions (23). These features, combined with the possibility to deliver therapeutic VHHs into the lung environment, and maintained stability after prolonged storage, make $\mathrm{VHH}$-based anti-influenza biologicals especially attractive for epidemic as well as pandemic preparedness plans (24-27).

In this study we explored a new strategy to engage host cell effector functions to combat influenza A. This strategy is based on a tail-to-head genetic fusion of two VHHs, one that selectively binds to Fc $\gamma$ RIV and a second one that is specific for M2e. The resulting bi-specific construct can be efficiently expressed in
Pichia pastoris cells and protects mice against an otherwise lethal influenza A virus infection by simple intranasal delivery.

\section{MATERIALS AND METHODS \\ Cell Lines and Culture Conditions}

HEK293T cells (a gift from Dr M. Hall, University of Birmingham, Birmingham, UK) and HEK293T cells stably transfected with influenza M2 (28) were cultured in Dulbecco's modified Eagle's medium supplemented with $10 \%$ of fetal calf serum, $2 \mathrm{mM}$ of L-glutamine, $0.4 \mathrm{mM}$ of Na-pyruvate, nonessential amino acids, $100 \mathrm{U} / \mathrm{ml}$ of penicillin and $10 \mu \mathrm{M}$ amantadine for the M2 expressing HEK cells. Madin-Darby canine kidney (MDCK) cells were cultured in Dulbecco's modified Eagle's medium supplemented with $10 \%$ of fetal calf serum, $2 \mathrm{mM}$ of L-glutamine, non-essential amino acids and 100 $\mathrm{U} / \mathrm{ml}$ of penicillin. Mf $4 / 4$ cells (an immortalized cell line of spleen macrophages derived from C57BL/6 mice) were grown in RPMI 1640 medium, supplemented with $10 \%$ of fetal calf serum, $2 \mathrm{mM}$ of L-glutamine, $0.4 \mathrm{mM}$ of Na-pyruvate, non-essential amino acids, $50 \mathrm{mM}$ 2-mercaptoethanol, $25 \mathrm{mM}$ Hepes and $100 \mathrm{U} / \mathrm{ml}$ of penicillin (29). Cloning of $\mathrm{Fc} \gamma \mathrm{R}-\zeta$ constructs, the generation of Fc $\gamma \mathrm{R}-\zeta$ BW5147 reporter cells and the culture conditions were similar as reported previously $(30,31)$.

\section{Production of Recombinant Mouse Fc $\gamma$ RIV Protein}

Recombinant Fc $\gamma$ RIV protein was produced by transient transfection of subconfluently grown FreesStyle ${ }^{\mathrm{TM}} 293-\mathrm{F}$ cells (ThermoFisher scientific) with pCAGGs expression vectors encoding the ectodomain of Fc $\gamma$ RIV (amino acids 1-201) coupled to a C-terminal 6XHis tag. Recombinant Fc $\gamma$ RIV protein was purified from the supernatant 6 days after transfection, using a $1 \mathrm{ml}$ HisTrap HP column (GE Healthcare). Fractions containing Fc $\gamma$ RIV protein were pooled and concentrated with a Vivaspin column (5 kDa cutoff, GE Healthcare) and then further purified by gel filtration on a Superdex 75 column. Fractions containing Fc $\gamma$ RIV protein were pooled and concentrated. Purity was evaluated by SDS-PAGE followed by Coomassie blue staining.

\section{Isolation of M2e-Binding, VHH-Displaying Phages}

A llama was immunized 6 times at weekly intervals subcutaneously with $150 \mu \mathrm{g}$ M2e-tGCN4 (28) in the presence of Gerbu LQ\#3000 adjuvant. Immunizations and handling of the llama were performed according to directive 2010/63/EU of the European parliament for the protection of animals used for scientific purposes and approved by the Ethical Committee for Animal Experiments of the Vrije Universiteit Brussel (permit No. 13-601-1). Five days after the last immunization, blood was collected and lymphocytes were prepared. Total RNA was extracted and used as template for the first strand cDNA synthesis with oligodT primer. The VHH encoding sequences were amplified from the cDNA and cloned into the Pst I and Not I sites of the phagemid vector pMECS. In this vector, the VHH coding sequence is followed by a linker, an $\mathrm{HA}-$ and $6 \mathrm{xHis}$ tag (AAAYPYDVPDYGSHHHHHH). 
Electro-competent E.coli TG1 cells were transformed with the recombinant pMECS vector resulting in a $\mathrm{VHH}$ library of about $10^{8}$ independent transformants. A library of $\mathrm{VHH}$-presenting phages was obtained after infection with VCS M13 helper phages. Two different panning strategies were used. In the first strategy, phages were added to $20 \mu \mathrm{g}$ of immobilized M2e-tGCN4 in panning round 1 and $20 \mu \mathrm{g}$ of human H3N2 peptide (SLLTEVETPIRNEWGCRCNDSSD) in panning round 2. In the second strategy, phages were first added to $25 \times 10^{6}$ HEK293T cells to deplete potential binders to determinants on these cells. The unbound phages were next added to $25 \times$ $10^{6}$ HEK293T cells stably transfected with influenza M2, to enrich for M2-specific phages. To avoid internalization of the target antigen, all steps were performed at $4^{\circ} \mathrm{C}$. After washing, retained phages were eluted by $\mathrm{pH}$ elution with TEA-solution (14\% triethylamine (Sigma) pH 10) for $10 \mathrm{~min}$. A solution of $1 \mathrm{M}$ Tris- $\mathrm{HCl} \mathrm{pH} 8$ was used to lower the $\mathrm{pH}$ of the eluted phage solution. The enrichment relative to panning on the negative control antigen, was determined by infecting TG1 cells with 10 -fold serial dilutions of the phages after which the bacteria were plated on LB agar plates with $100 \mu \mathrm{g} / \mathrm{ml}$ ampicillin and $1 \%$ glucose.

\section{Isolation of Fc $\gamma$ RIV-Binding, VHH-Displaying Phages}

The Fc $\gamma$ RIV specific VHHs were isolated form a library that was part of a study described elsewhere by Deschacht et al. (32). In brief, a llama was immunized six times at weekly intervals with $10^{8}$ immature murine bone marrow-derived dendritic cells. A library of VHH-presenting phages was obtained as described above. Fc $\gamma$ RIV specific VHHs were enriched after three panning rounds on $20 \mu \mathrm{g}$ of immobilized Fc $\gamma$ RIV protein.

\section{Periplasmic ELISA Screen to Identify M2e- and Fc $\gamma$ RIV-Specific VHHs}

After panning, individual pMEC colonies were randomly selected for further analysis by ELISA for the presence of M2eand Fc $\gamma$ RIV-specific VHHs in their periplasm. To prepare periplasmic extract, individual colonies were inoculated in $2 \mathrm{ml}$ of terrific broth (TB) medium with $100 \mu \mathrm{g} / \mathrm{ml}$ ampicillin in 24 -well deep well plates. After $5 \mathrm{~h}$ incubation isopropyl $\beta$-D-1thiogalactopyranoside (IPTG) $(1 \mathrm{mM})$ was added to induce $\mathrm{VHH}$ expression. After overnight incubation at $37^{\circ} \mathrm{C}$, bacterial cells were pelleted and resuspended in $200 \mu \mathrm{l}$ TES buffer $(0.2 \mathrm{M}$ Tris$\mathrm{HCl} \mathrm{pH} \mathrm{8,} \mathrm{0.5} \mathrm{mM} \mathrm{EDTA,} 0.5 \mathrm{M}$ sucrose) and incubated at $4^{\circ} \mathrm{C}$ for $30 \mathrm{~min}$. An osmotic shock was induced by adding $300 \mu \mathrm{l}$ of water. After $1 \mathrm{~h}$ incubation at $4^{\circ} \mathrm{C}$ followed by centrifugation, the periplasmic extract was collected. $\mathrm{VHH}$-containing periplasmic extracts were then tested for binding to either M2e-tGCN4 (28), human H3N2 M2e peptide (SLLTEVETPIRNEWGCRCNDSSD) or recombinant mouse Fc $\gamma$ RIV protein. Briefly, wells of microtiter plates were coated overnight with either $100 \mathrm{ng}$ M2e-tGCN4, 100 ng mouse Fc $\gamma$ RIV protein, bovine serum albumin (BSA, Sigma-Aldrich) at $4^{\circ} \mathrm{C}$ or $100 \mathrm{ng}$ human $\mathrm{H} 3 \mathrm{~N} 2$ $\mathrm{M} 2 \mathrm{e}$ peptide at $37^{\circ} \mathrm{C}$. The coated plates were blocked with $5 \%$ milk powder in phosphate buffered saline (PBS) and
$100 \mu \mathrm{l}$ of the periplasmic extract was added to the wells. Bound VHHs were detected with anti-HA mAb (1/2000, MMS101P Biolegend) followed by horseradish peroxidase (HRP)linked anti-mouse IgG (1/2000, NXA931, GE Healthcare). All periplasmic fractions, which resulted in $\mathrm{OD}_{450}$ values of the antigen coated wells that were at least two times higher than the $\mathrm{OD}_{450}$ values obtained in BSA coated wells, were selected. DNA of the selected colonies was isolated using the QIAprep Spin Miniprep kit (Qiagen) and sequenced using the primer MP057(5' -TTATGCTTCCGGCTCGTATG-3').

\section{VHH Expression in Pichia pastoris}

The VHH encoding sequence was amplified by PCR using the following forward and reverse primer $\left(5^{\prime}\right.$-GGC GGG TAT CTC TCG AGA AAA GGC AGG TGC AGC TGC AGG AGT CTG GG-3') and (5' - CTA ACT AGT CTA GTG ATG GTG ATG GTG GTG GCT GGA GAC GGT GAC CT GG-3'). The PCR fragments were then cloned between the XhoI and SpeI sites in the pKai61 expression vector [described by Schoonooghe et al. (33)]. In the vector, the VHHs sequences containing a C-terminal 6XHis tag sequence are under control of the methanol inducible AOX1 promotor and in frame with a modified version of the $S$. cerevisiae $\alpha$-mating factor prepro signal sequence. The vector contains a Zeocine resistance marker for selection in bacteria as well as in yeast cells. The vectors were linearized by PmeI and transformed in the $P$. pastoris strain GS115 using the condensed transformation protocol described by Lin-Cereghino et al. (34) After transformation, the yeast cells were plated on YPD plates $(1 \%(\mathrm{w} / \mathrm{v})$ yeast extract, $2 \%(\mathrm{w} / \mathrm{v})$ peptone, $2 \%(\mathrm{w} / \mathrm{v})$ dextrose, and $2 \%(\mathrm{w} / \mathrm{v})$ agar) supplemented with zeocin $(100 \mu \mathrm{g} / \mathrm{ml})$ for selection.

\section{VHH Production and Purification}

The transformed $P$. pastoris clones were first analyzed for $\mathrm{VHH}$ expression in $2 \mathrm{ml}$ cultures. On day one, 2-5 clones of each construct were inoculated in $2 \mathrm{ml}$ of YPNG medium (2\% pepton, $1 \%$ Bacto yeast extract, $1.34 \% \mathrm{YNB}, 0.1 \mathrm{M}$ potassium phosphate $\mathrm{pH} 6,1 \%$ glycerol) with $100 \mu \mathrm{g} / \mathrm{ml}$ Zeocin (Life Technologies) and incubated at $28^{\circ} \mathrm{C}$ for $24 \mathrm{~h}$. The next day, the cells were pelleted by centrifugation and the medium was replaced by YPNM medium (2\% pepton, $1 \%$ Bacto yeast extract, $1.34 \% \mathrm{YNB}, 0.1 \mathrm{M}$ potassium phosphate $\mathrm{pH} 6.0,1 \%$ methanol). Cultures were incubated at $28^{\circ} \mathrm{C}$ and $50 \mu$ l of $50 \%$ methanol was added at 16,24 , and $40 \mathrm{~h}$. After $48 \mathrm{~h}$, the supernatant was collected and the presence of soluble VHHs in the supernatant was verified using SDS-PAGE and subsequent Coomassie Blue staining. Production was scaled up $(300 \mathrm{ml})$ for the transformants with the highest levels of $\mathrm{VHH}$ in the medium. Growth and methanol induction conditions and harvesting of medium were similar as mentioned above for the $2 \mathrm{ml}$ cultures. The secreted VHHs in the medium were precipitated by ammonium sulfate $\left(\mathrm{NH}_{4}\right)_{2} \mathrm{SO}_{4}$ precipitation (80\% saturation) for $4 \mathrm{~h}$ at $4{ }^{\circ} \mathrm{C}$. The insoluble fraction was pelleted by centrifugation at 20,000 $\mathrm{g}$ and resuspended in $10 \mathrm{ml}$ binding buffer $\left(20 \mathrm{mM} \mathrm{NaH}_{2} \mathrm{PO}_{4} \mathrm{pH} 7.5\right.$, $0.5 \mathrm{M} \mathrm{NaCl}$ and $20 \mathrm{mM}$ imidazole $\mathrm{pH}$ 7.4). The VHHs were purified from the solution using a $1 \mathrm{ml}$ HisTrap HP column (GE Healthcare). Bound VHHs were eluted with a linear imidazole 
gradient starting from $20 \mathrm{mM}$ and ending at $500 \mathrm{mM}$ imidazole in binding buffer over a total volume of $20 \mathrm{ml}$. VHH containing fractions were pooled and concentrated with a Vivaspin column ( $5 \mathrm{kDa}$ cutoff, GE Healthcare) and then further purified by gel filtration (Superdex 75) in PBS buffer. Fractions containing VHH were again pooled and concentrated. Purity was evaluated by SDS-PAGE followed by Coomassie blue staining.

\section{Enzyme-Linked Immunosorbent Assay}

Wells of microtiter plates were coated overnight with either 100 ng M2e-tGCN4, 100 ng BM2e-tGCN4, 100 ng M2e peptide or 100 ng mouse Fc $\gamma$ RIV protein. The coated plates were blocked with $5 \%$ milk powder in phosphate buffered saline (PBS) and dilution series of the VHHs were added to the wells. In the M2e ELISA, bound VHHs were detected with mouse anti-Histidine Tag antibody (MCA1396, Abd Serotec) followed by horseradish peroxidase (HRP)-linked anti-mouse IgG (1/2000, NXA931, GE Healthcare). In the ELISA with coated recombinant Fc $\gamma$ RIV protein, binding was detected with a HRP conjugated rabbit anticamelid VHH antibody (A01861-200, GenScript). After washing $50 \mu \mathrm{l}$ of TMB substrate (Tetramethylbenzidine, BD OptETA) was added to every well. The reaction was stopped by addition of $50 \mu \mathrm{l}$ of $1 \mathrm{M} \mathrm{H}_{2} \mathrm{SO}_{4}$, after which the absorbance at $450 \mathrm{nM}$ was measured with an iMark Microplate Absorbance Reader (Bio Rad).

\section{Crystallization of M2e-VHH-23m in Complex With M2e Peptide}

For crystallization, the purified $\mathrm{M} 2 \mathrm{e}-\mathrm{VHH}-23 \mathrm{~m}$ was concentrated to $20 \mathrm{mg} / \mathrm{ml}$. The M2e peptide was added in a 1.2 times excess. Crystallization screens were set up in sitting drop vapor diffusion at $20^{\circ} \mathrm{C}$. Crystals grown in the Jenna Classic screen, in 30\% ethanol, 10\% PEG6000, $100 \mathrm{mM} \mathrm{Na}$ acetate were cryoprotected using fluorosilicone and flash frozen in liquid nitrogen. X-ray data were collected at the i03 beamline of the Diamond Light Source synchrotron facility and processed using XDS. ${ }^{47}$

The structure of the M2e-VHH-23m-M2e peptide complex was solved using the structure of another nanobody (PDB code 5 HGG) as search model for molecular replacement, using the Phaser program from the CCP4 crystallographic software suite (35, 36). The M2e-VHH-23m model was built automatically using Autobuild from the Phenix crystallographic software suite (37). The initial model was further built manually in Coot and refined using phenix.refine and Refmac (38-40). Data collection parameters, as well as processing and refinement statistics are shown in Table 1. The crystal structure has been deposited in the Protein Data Bank (PDB) and is available with accession code $6 \mathrm{~S} 0 \mathrm{Y}$.

\section{Docking}

All water molecules, the ligand, and chain B of the nanobody crystal structure were manually deleted from the pdb-text file. The emptied structure was subjected to a local minimization with the GROMOS96 (43B1 parameter set) implementation within Swiss-PdbViewer 4.1.0 (41), and polar hydrogens were added. The peptide-ligand VETPIRNEWG was 3D-drawn with
TABLE 1 | Data collection statistics and refinement parameters.

\begin{tabular}{|c|c|}
\hline \multicolumn{2}{|l|}{ Data collection } \\
\hline Synchrotron & Diamond Light Source \\
\hline Beamline & i03 \\
\hline Wavelength, $\AA$ & 0.97965 \\
\hline \multicolumn{2}{|l|}{ Data processing } \\
\hline Space group & P 21212 \\
\hline Cell parameters, $\AA\left(\alpha=\beta=\gamma=90^{\circ}\right)$ & 57.4794 .7653 .06 \\
\hline Resolution, $\AA$ (outer shell) (c) & $53.06-1.80(1.83-1.80)$ \\
\hline Total reflections & 35827 (17918) \\
\hline No. of unique reflections & 27557 (1359) \\
\hline Completeness & $99.97(100)$ \\
\hline Multiplicity & $13.0(13.2)$ \\
\hline$R_{\text {pim }}, \%$ & $4.4(66.6)$ \\
\hline $\mathrm{CC}_{1 / 2}, \%$ & $99.8(57.1)$ \\
\hline$<I / \sigma(I)>$ & $11.0(1.1)$ \\
\hline Mosaicity, ${ }^{\circ}$ & $0.063^{\circ}$ \\
\hline \multicolumn{2}{|l|}{ Refinement } \\
\hline Resolution range, $\AA$ & $47.38-1.81$ \\
\hline No. of reflections & 25859 \\
\hline Percentage observed & 99.96 \\
\hline $\mathrm{R}_{\text {cryst }},{ }^{(a)} \%$ & 18.69 \\
\hline $\mathrm{R}_{\text {free }}{ }^{(b)} \%$ & 22.53 \\
\hline \multicolumn{2}{|l|}{ RMS } \\
\hline Bonds, ^ & 0.01 \\
\hline Angles, ${ }^{\circ}$ & 1.66 \\
\hline \multicolumn{2}{|l|}{ Ramachandran Plot } \\
\hline Most favored, \% & 95.28 \\
\hline Additionally allowed, \% & 4.72 \\
\hline Disallowed, \% & 0 \\
\hline PDB code & 6SOY \\
\hline
\end{tabular}

(a) $R_{\text {cryst }}=\Sigma\left(\left|F_{\text {obs }}\right|-\left|F_{c a l c}\right|\right) / \Sigma\left|F_{\text {obs }}\right|, F_{\text {obs }}$ and $F_{\text {calc }}$ are observed and calculated structure factor amplitudes.

(b) $R_{\text {free }}$ as for $R_{\text {cryst }}$ using a random subset of the data excluded from the refinement.

(c) Data in brackets are for the highest resolution shell.

Avogadro 1.2.0 (42) and minimized with the built-in united force field. The AutoDockTools 1.5.6 suite (43) was used for pdbqtformat conversions and grid-box determination. The grid-box size was $\mathrm{x}=22, \mathrm{y}=30$ and $\mathrm{z}=20$ centered at $\mathrm{x}=1.9, \mathrm{y}=$ 9.7 and $z=8.3$. Docking was performed with Smina $(44,45)$ with exhaustiveness set at 128 . Visualization was with PyMOL 2.3.0 (46).

\section{Isothermal Titration Calorimetry}

M2e-VHH-23m was dialyzed overnight against PBS buffer and concentrated using Amicon Ultra $3 \mathrm{kDa}$ cut off centrifugal filter devices. The M2e peptide was resuspended in PBS at a stock concentration of $3 \mathrm{mM}$, and diluted in PBS to $300 \mu \mathrm{M}$. Titrations comprised $26 \times 1.5 \mu \mathrm{L}$ injections of peptide $(300 \mu \mathrm{M})$ into the protein $(30 \mu \mathrm{M})$, with $90 \mathrm{~s}$ intervals. An initial injection of ligand $(0.5 \mu \mathrm{L})$ was made and discarded during data analysis. The data were fitted to a single binding site model using the Microcal LLC ITC $_{200}$ Origin software provided by the manufacturer. 


\section{Ala Scan Mutagenesis}

HEK293T cells were transiently transfected with Flag-tagged M2 wild type (WT) and M2e Ala scan mutants. $24 \mathrm{~h}$ after infection the cells were detached, washed and blocked. Cells were stained with $20 \mu \mathrm{g} / \mathrm{ml}$ M2e VHH-23m or $20 \mu \mathrm{g} / \mathrm{ml} \mathrm{F-}$ VHH-4 and subsequently fixed with $2 \%$ paraformaldehyde. After permeabilization $(10 \times$ permeabilization buffer diluted in doubledistilled water; eBioscience), cells were stained with mouse antiHistidine tag antibody (MCA1396, Abd Serotec) and rabbit anti-Flag tag antibody (F7425, Sigma-Aldrich). Binding of the primary antibodies was revealed with donkey anti-mouse IgG coupled to Alexa Fluor 647 (1/600; Invitrogen) and donkey anti-rabbit IgG coupled to Alexa Fluor 488 (1/600; Invitrogen). The median fluorescence intensity (MFI) of the cells was determined with an LSRII HTS flow cytometer (BD) and was calculated by subtracting the median fluorescence of binding of M2e-VHH-23m or F-VHH-4 to transfected cells from the median fluorescence of untransfected cells bound by M2e-VHH$23 \mathrm{~m}$ or $\mathrm{F}-\mathrm{VHH}-4$.

\section{VHH Binding to Influenza A Virus Infected Cells}

HEK293T cells were mock-infected or infected with A/Puerto Rico/8/1934 (H1N1), A/X47 (H3N2), A/Udorn/307/1972 (H3N2) or A/Swine/Ontario (H3N3) at a MOI of 1 . Twenty-four hours after infection the cells were detached, washed and blocked. Cells were stained with $20 \mu \mathrm{g} / \mathrm{ml}$ M2e VHH-23m, $20 \mu \mathrm{g} / \mathrm{ml} \mathrm{F-VHH}-4$ or $10 \mu \mathrm{g} / \mathrm{ml} \mathrm{MAb148.} \mathrm{To} \mathrm{determine} \mathrm{the}$ affinity of M2e-VHH-23m on infected cells, $1 / 3$ dilution series of $\mathrm{M} 2 \mathrm{e}-\mathrm{VHH}-23 \mathrm{~m}$ or F-VHH4 were applied to A/Puerto Rico/8/1934 (H1N1) infected cells. Subsequently, the cells were fixed with $2 \%$ paraformaldehyde and stained with mouse anti-Histidine Tag antibody (MCA1396, Abd Serotec) and goat anti-A/Puerto Rico/8/1934 serum (Biodefense and Emerging Infections Resources Repository, NIAID, NIH, V314-511-157) followed by anti-mouse IgG Alexa 488 (Invitrogen) and anti-goat IgG Alexa 647 (Invitrogen). The median fluorescence intensity (MFI) was measured on the LSRII-tubes flow cytometer (BD) and was calculated by subtracting the median fluorescence of binding of M2e-VHH-23m or F-VHH-4 to infected cells from the median fluorescence of uninfected cells bound by M2e-VHH-23m or F-VHH-4.

\section{Plaque Reduction Assay}

Different amounts of M2e-VHH-23m $(2.5 \mu \mathrm{M}, 1.25 \mu \mathrm{M}$ or $0.625 \mu \mathrm{M}), 0.333 \mu \mathrm{M} \mathrm{MAb37}$ or sera of mice infected with A/Puerto Rico/8/1934 (H1N1) virus were incubated for $1 \mathrm{~h}$ at $4^{\circ} \mathrm{C}$ with $10-20$ plaque forming units/well of A/Udorn/307/1972 (H3N2) or A/Puerto Rico/8/1934 (H1N1) virus. After incubation, the mixture was added to MDCK cells, seeded in a flat bottom 24-well plate. After $1 \mathrm{~h}$, the cells were overlaid with an equal volume of $1.2 \%$ Avicel RC-591 (FMC Biopolymer) supplemented with $2 \mu \mathrm{g} / \mathrm{ml}$ of TPCK-treated trypsin (Sigma). Infection was allowed for 2 days at $37^{\circ} \mathrm{C}$ in $5 \% \mathrm{CO}_{2}$. The overlay was subsequently removed and the cells were fixed with $4 \%$ paraformaldehyde. Viral plaques were stained with convalescent mouse anti- A/Puerto Rico/8/34 or A/Udorn/307/72 serum followed by horseradish peroxidase (HRP)-linked anti-mouse IgG (NXA931, GE Healthcare). Finally, after washing, the plaques were visualized with TrueBlue peroxidase substrate (KPL, Gaithersburg).

\section{VHH Binding to Fc $\gamma$ Rs Expressing Cells}

Human Embryonic Kidney (HEK) 293T cells were transiently transfected with full length mouse Fc $\gamma$ RI (MG50086-CF), Fc $\gamma$ RIIb (MG50030-CY, SinoBiological Inc.), Fc $\gamma$ RIII (MG50326, SinoBiological Inc.) or Fc $\gamma$ RIV (MG50036-CF, SinoBiological Inc.) expression constructs along with the common $\gamma$-chain for the activating Fc $\gamma$ Rs (MG50935-CF) by polyethylenimine (PEI)based transfection. A GFP-reporter plasmid was co-transfected. Fc $\gamma$ RIV-VHH-7m and M2e-VHH-23m were directly labeled with the Alexa Fluor ${ }^{\mathrm{TM}} 647$ antibody labeling kit (A20186, ThermoFisher scientific). Of the labeled VHHs, $0.2 \mu \mathrm{M}$ or $1 / 4$ serial dilution series of the VHHs starting from $0.2 \mu \mathrm{M}$ were added to the transfected cells or Mf4/4 cells (29). Fluorescence was measured on an LSRII flow cytometer (BD). The median fluorescence intensity (MFI) was calculated by subtracting the median fluorescence of binding of M2e-VHH$23 \mathrm{~m}$ or Fc $\gamma$ RIV-VHH-7m to transfected cells from the median fluorescence of untransfected cells bound by M2e-VHH-23m orFc $\gamma$ RIV-VHH-7m.

\section{Construction of Bispecific VHHs}

To construct Fc $\gamma$ RIV VHH-M2e VHH, Fc $\gamma$ RIV VHH-F VHH, and Fc $\gamma$ RIIIa VHH-M2e VHH bispecific VHHs, we made use of a GoldenBraid-based cloning strategy (47). The coding information of Fc $\gamma$ RIV-VHH-7m or Fc $\gamma$ RIIIa VHH [C28 sdAb, described by Behar et al. (48)] was amplified with the following forward (5' - GCG ATG CAG GGT CTC ACT TCA AGG CAG GTG CAG CTG CAG GAG TC-3') and reverse primer (5' GGC GAT GGT GGG TCT CAC TTC ATG AGG AGA CGG TGA CCT GGG-3') that add specific overhangs for their identity as $\mathrm{N}$-terminal $\mathrm{VHH}$ together with a $B s a \mathrm{I}$ and SapI restriction site. The C-terminal VHHs, M2e-VHH-23m and F-VHH-4 were amplified with a forward ( $5^{\prime}$-GCG CGA TGC AGG GTC TCA CTT CAC AGG TGC AGC TGC AGG AG TC-3') and reverse primer $\left(5^{\prime}\right.$-GGG CGA TGG TGG GTC TCA CTT CAA GTC TAG TGA TGG TGA TGG TGG TGG CTG GAG ACG GTG ACC TG GG-3') that add specific overhangs for their identity as C-terminal VHH together with a $B s a \mathrm{I}$ and SapI restriction site. The 15 amino acid long $\left(\mathrm{Gly}_{4} \mathrm{Ser}\right)_{3}$ linker was generated with the following forward (5' - GCG ATG CAG GGT CTC ACT TCA TCA GGC GGA GGC GGT AGT GGC GGA GGT GGA TCT GGA GGC GGC GGT AGT CA GT-3') and reverse primer $\left(5^{\prime}\right.$ GGC GAT GGT GGG TCT CAC TTC ACT GAC TAC CGC CGC CTC CAG ATC CAC CTC CGC CAC TAC CGC CTC CGC CTG AT- $3^{\prime}$ ) that also add a specific overhang together with a $B s a \mathrm{I}$ and SapI restriction site. The PCR amplified fragments were each assembled in a PUPD2 entry vector by a $B s a \mathrm{I}$ restriction and ligation reaction. Once stored in the pUPD2 vector, the different parts were assembled together in the pKai61 expression vector using a T4 DNA ligase and a SapI restriction enzyme which recognizes the SapI restriction site which was introduced after ligation into the pUPD2 vector. 


\section{In vitro Fc $\gamma \mathrm{R}$ Activation Assay}

Fc $\gamma R$ activation by MAbs 37 and 65 as well as by different $\mathrm{M} 2 \mathrm{e}$-specific nanobodies was determined using an in vitro $\mathrm{Fc} \gamma \mathrm{R}$ activation assay $(13,30,31)$. Cloning of $\mathrm{Fc} \gamma \mathrm{R}-\zeta$ constructs and the generation of Fc $\gamma \mathrm{R}-\zeta$ BW5147 reporter cells were performed as reported previously $(30,31)$. Activation of stably transduced Fc $\gamma \mathrm{R}-\zeta$ BW5147 reporter cells by immune complexes results in the production of mouse interleukin-2 (mIL-2), which was quantified by ELISA $(30,31)$.

HEK293T cells that were stably transfected with an M2 expression vector (28) were cultured in the presence of $10 \mu \mathrm{M}$ amantadine. The cells were seeded 1 day before the coculture experiment in 96-well flat-bottom plates, pre-coated with fibronectin purified from human plasma $(4 \mu \mathrm{g} / \mathrm{ml}$ diluted in PBS). The next day, serial dilutions of the respective MAbs or $\mathrm{VHH}$ fusion constructs (concentrations as indicated ranging from 4 to $0.0625 \mu \mathrm{g} / \mathrm{ml}$ ) were added to the HEK293T-M2 and incubated for $30 \mathrm{~min}$ at $37^{\circ} \mathrm{C}$, followed by the addition of $1.5 \times$ $10^{5} \mathrm{Fc} \gamma \mathrm{R}-\zeta$ BW5147 reporter cells in a total volume of $200 \mu \mathrm{l}$ RPMI1640 medium with 10\% fetal calf serum per well. Target cells and reporter cells were incubated overnight at $37^{\circ} \mathrm{C}$ in a $5 \%$ $\mathrm{CO}_{2}$ atmosphere to allow mIL-2 production. Supernatants were analyzed by an anti-mIL-2 sandwich ELISA as described using the capture MAb JES6-1A12 and the biotinylated detection MAb JES6-5H4 (BD Pharmingen ${ }^{\mathrm{TM}}$, Belgium) $(30,31)$.

For infection with influenza A/Puerto Rico/8/1934 virus, Madin-Darby canine kidney (MDCK) cells were seeded in 96well flat-bottom plates and infected with influenza PR8 virus (multiplicity of infection [MOI], 5). After $1 \mathrm{~h}$ of incubation at $37^{\circ} \mathrm{C}$, unbound virus particles were removed by washing, and serial dilutions of the respective MAbs or VHHs (concentrations ranging from 4 to $0.0625 \mu \mathrm{g} / \mathrm{ml}$ ) were added and incubated for $30 \mathrm{~min}$ at $37^{\circ} \mathrm{C}$, followed by the addition of $1.5 \times 10^{5}$ Fc $\gamma \mathrm{R}-\zeta$ BW5147 reporter cells in a total volume of $200 \mu \mathrm{l}$ RPMI1640 medium with 10\% fetal calf serum per well. Target cells and reporter cells were incubated overnight at $37^{\circ} \mathrm{C}$ in a $5 \% \mathrm{CO}_{2}$ atmosphere to allow mIL-2 production. Supernatants were analyzed by an anti-IL-2 sandwich ELISA as described $(30,31)$. If not indicated otherwise, experiments were performed in triplicates.

\section{Challenge Experiments in Mice}

All experiments were approved by and performed according to the guidelines of the animal ethical committee of Ghent University (Ethical applications EC2017-66 and EC2018-12). Female BALB/c mice and male and female C57BL/6 mice were purchased from Charles River (France) and $F c \gamma R I V^{-/-}$C57BL/6 mice (49) were bred in-house under specified-pathogen-free conditions. Mice were used at age 6-12 weeks and were SPFhoused with food and water ad libitum. Mice were anesthetized with isoflurane for treatment and infection. The mice were treated $4 \mathrm{~h}$ before and $24 \mathrm{~h}$ after influenza A virus challenge by intranasal administration of $50 \mu \mathrm{g}$ of the bispecific VHHs in a volume of $50 \mu \mathrm{l}$ PBS. Mice were challenged with $2 \mathrm{xLD}_{50}$ of A/X47 (H3N2) influenza virus. Body weight loss was monitored for 14 days. To determine the lung viral titer, complete lungs were harvested on day 6 after infection and homogenized in
$1 \mathrm{ml}$ of PBS with a sterile metal bead on the Mixer Mill MM 200 (Retsch). After clearance by centrifugation at $4^{\circ} \mathrm{C}$, the lung homogenates were used for virus titration by plaque assay. The plaque assay was performed as described before, plaques were stained using convalescent mouse anti-X47 serum followed by horseradish peroxidase (HRP)-linked anti-mouse IgG (NXA931, GE Healthcare).

\section{Statistical Analysis}

Statistical comparison of the differences in body weight loss was analyzed as repeated measurements data using the residual maximum likelihood (REML) as implemented in Genstat v19. Briefly, a linear mixed model (random terms underlined) of the form $y=\mu+$ experiment + treatment + time + treatment.time + mouse.time was fitted to the longitudinal data. The term mouse.time represents the residual error term with dependent errors because the repeated measurements are taken in the same individual, causing correlations among observations. Times of measurement were set as equally spaced, and the autoregressive model of order 1 was selected as the best correlation model based on the Aikake Information Coefficient. Significances of treatment effects across time (i.e., treatment.time) and of pairwise differences between treatment effects across time were assessed by an approximate $F$-test, of which the denominator degrees of freedom were calculated using algebraic derivatives as implemented in Genstat v19.

Survival analysis was performed on the right-censored survival data obtained for the five treatment groups. Groups were compared using the nonparametric log-rank test as implemented in Genstat v19. The two independent experiments were set as different groupings for a stratified test.

For the statistical analysis of the differences in lung viral titers a Hierarchical Generalized Linear Mixed Model (HGLMM; fixed model: poisson distribution, log link; random model: gamma distribution, log link) as implemented in Genstat v19 (see ref below), was fitted to the titer data. Treatment, having five levels, was set as fixed term, while replicate was set as random term. $\mathrm{T}$ statistics were used to assess the significance of treatment differences compared with the Fc $\gamma$ RIV VHH-F VHH set as reference level (on the log-transformed scale). Estimated mean values and standard errors were obtained as predictions from the HGLMM, formed on the original scale of the response variable.

\section{Conservation of the M2 Ectodomain Sequences in Human H3N2 Influenza A Viruses}

All complete M2 protein sequences of human $\mathrm{H} 2 \mathrm{~N} 2$ viruses, human $\mathrm{H} 3 \mathrm{~N} 2$ viruses and human $\mathrm{H} 1 \mathrm{~N} 1$ influenza $\mathrm{A}$ viruses circulating between 1933 and 2008 were extracted from the Influenza Research Database (http://www.fludb.org/) on 3th May 2019.

\section{RESULTS}

\section{Isolation of M2e-Specific VHHs}

To generate M2e-specific VHHs a llama was immunized repeatedly with $\mathrm{M} 2 \mathrm{e}-\mathrm{tGCN} 4$ protein, a soluble recombinant 
immunogen that mimics the natural tetrameric M2e conformation, that was previously shown to induce protective M2e-specific IgG antibodies in mice $(28,50)$. Five days after the last immunization, peripheral blood lymphocytes were isolated from the llama and an immune $\mathrm{VHH}$ phagemid library of about $10^{8}$ clones was generated. M2e-specific VHHs were enriched from this library by sequential panning on immobilized M2e-tGCN4 (round 1) and M2e peptide (SLLTEVETPIRNEWGCRCNDSSD, corresponding to M2e of human $\mathrm{H} 3 \mathrm{~N} 2$ viruses) (round 2). As a second strategy, M2e-specific VHHs were enriched by panning on HEK293T cells that stably express M2. Individual phagemid clones enriched after both panning strategies were randomly selected and tested for binding to M2e-tGCN4 and M2e peptide in ELISA. Sequence analysis of the $\mathrm{VHH}$ encoding clones which tested positive for binding to either M2e-tGCN4 or M2e peptide revealed a low sequence diversity. Two clones (M2e-VHH-23m and $\mathrm{M} 2 \mathrm{e}-\mathrm{VHH}-66 \mathrm{~m}$ ) isolated with the first, and one clone (M2e-VHH-10m) isolated with the second panning strategy, were selected for further characterization. These VHHs had a cysteine residue at position 50 in the CDR2 and position $100 \mathrm{~b}$ in the CDR3 (Kabat numbering), allowing the formation of an additional stabilizing disulfide bound, and were devoid of $\mathrm{N}$-glycosylation sequons (Figure 1A) (51). The M2e-specific VHHs and an irrelevant control F-VHH-4 directed against the F protein of human respiratory syncytial virus, were subsequently expressed in Pichia pastoris in a secreted format (52). After purification from the yeast medium, the epitope specificity was assessed by ELISA. M2e-VHH-23m and M2e-VHH-66m bound to M2e-tGCN4 with a relatively high affinity, whereas M2e-VHH-10m displayed weaker binding (Figure 1B). None of the VHHs bound to purified recombinant influenza B M2 ectodomain fused to tGCN4, suggesting that the VHHs bind to M2e. The three selected VHHs bound to immobilized M2epeptide in ELISA. Amino-acid residues 10 to 23 of M2(e) display some sequence diversity (50). We therefore tested binding of the VHHs to peptide variants that correspond to M2e from A/Brevig Mission/1918 (H1N1), A/Hong Kong/485/1997 (H5N1) and A/swine/Belgium/1/1998 (H1N1) (Figure 1B). None of the purified VHHs bound to these M2e peptides, whereas a control mouse monoclonal antibody (MAb148) that is specific for the extremely conserved amino-terminus of M2 (SLLTEVET) did bind (Figure 1B). This indicates that the isolated VHHs can bind to M2 expressed by human $\mathrm{H} 2 \mathrm{~N} 2$, the majority of human $\mathrm{H} 3 \mathrm{~N} 2$ strains and the majority of human H1N1 viruses circulating between 1933 and 2008 but are unlikely to recognize M2 of currently circulating human $\mathrm{H} 1 \mathrm{~N} 1$ viruses or most avian and swine influenza viruses. Remarkably, the isolated VHHs also failed to bind the H1N1 A/Brevig Mission/1/1918 M2e, which suggests that Ile11 in M2e contributes substantially to binding. We selected $\mathrm{M} 2 \mathrm{e}-\mathrm{VHH}-23 \mathrm{~m}$ to target $\mathrm{M} 2 \mathrm{e}$ in the subsequent experiments.

\section{M2e-Specific VHH Clamps M2e Peptide Between Its CDR2 and CDR3}

We performed isothermal titration calorimetry (ITC) experiments to determine the binding affinity of $\mathrm{M} 2 \mathrm{e}-\mathrm{VHH}-23 \mathrm{~m}$ to the human $\mathrm{H} 3 \mathrm{~N} 2$ M2e peptide. The data revealed a 1:1 biomolecular association between the $\mathrm{VHH}$ and the M2e peptide with a $K_{d}$ value of $730 \mathrm{nM}$ (Figure 2). The affinity of the single domain M2e-VHH-23m is thus over a 1,000-fold lower than the previously reported affinities for the M2e-specific mouse monoclonal antibodies MAb65 and MAb37 (13).

To precisely resolve the epitope of $\mathrm{M} 2 \mathrm{e}-\mathrm{VHH}-23 \mathrm{~m}$, we determined the crystal structure of this $\mathrm{VHH}$ in complex with human $\mathrm{H} 3 \mathrm{~N} 2 \mathrm{M} 2 \mathrm{e}$ peptide to $1.81 \AA$ resolution (Table 1, PDB code $6 \mathrm{~S} 0 \mathrm{Y})$. M2e-VHH-23m binds the M2e N-terminus as a linear epitope (Figure 3A, left panel). In the crystal structure, one M2e peptide interacts with three adjacent M2e-VHH-23m molecules at three respective interfaces (Figure S1). M2e residues E6 to N13 bind in a shallow groove formed by CDR3, CDR2 and the main body of the $\mathrm{VHH}$ formed by $\beta$-strands $\mathrm{C}, \mathrm{C}$, C", and F (Interface 1; Figure 3A). As expected, based on the $\mathrm{VHH}$ sequence data, a stabilizing disulfide bridge is observed between the CDR3 and CDR2 (Figure 3A). Interface 1 includes hydrogen bonds between the M2e-VHH-23m residues Arg45Gln46-Gly47 and M2e residues Glu8 and Thr9, M2e-VHH-23m residue Cys100b and $\mathrm{M} 2 \mathrm{e}$ residue $\mathrm{Ile11}$, and $\mathrm{M} 2 \mathrm{e}-\mathrm{VHH}-23 \mathrm{~m}$ residue Glu100 and M2e residues Arg12 and Asn13. In addition, three hydrophobic contacts are formed: (1) M2e residue Val7 binds a shallow pocket lined by residue Phe37, Val100f and Trp103, (2) Pro10 stacks against Tyr100d, and (3) the side chain of $\mathrm{M} 2 \mathrm{e}$ residue IIe11 is inserted in a pocket formed by the side chain of IIe58 of the VHH CDR2, and the backbones of Tyr59 (CDR2), Gly47, Val48 and Ser49 (CDR3). De bottom of the latter pocket is formed by the stabilizing disulfide bridge between Cys50 in CDR2 and Cys100b in CDR3 (Figure 3A). In interface 2, M2e residues 14 to 19 lie on a surface formed by CDR2 and CDR3. The highly conserved M2e Trp15 side chain is inserted in a deep pocket formed by residues from the 3 CDRs: the side chains of Ile58 and Tyr97, and backbones of Ile51, Gly56, Thr57, Asn98, Val99, and Gly100a. In addition, the imidazole NH of Trp15 is hydrogen bonded to the backbone of Asn98 (Interface 2, Figure 3B).

In the crystals, the $\mathrm{M} 2 \mathrm{e}$ peptide contacts three adjacent molecules in an interaction reminiscent of domain swapping (53). Closer inspection indeed suggests that ligand swapping occurs between the M2e peptides bound to symmetry related molecules in the crystal (Figure S2). Docking experiments using the VETPIRNEWG M2e peptide show that the Interface 1 and 2 regions of the M2e peptide (residues 6-12 and 1419 , respectively) can bind a single $\mathrm{M} 2 \mathrm{e}-\mathrm{VHH}-23 \mathrm{~m}$ molecule (Figure 3C). This is also supported by ITC experiments indicating that in solution $\mathrm{M} 2 \mathrm{e}-\mathrm{VHH}-23 \mathrm{~m}$ and $\mathrm{M} 2 \mathrm{e}$ interact in a 1:1 stoichiometry (Figure 2). To validate the relative importance of the two binding interfaces in this interaction, we additionally tested the binding of M2e-VHH-23m to HEK293T cells expressing M2 protein or M2e Ala-mutants by flow cytometry (Figure 3D). M2e-VHH-23m did not bind to cell that were transfected with an M2Ile11Ala or M2Trp15Ala expression construct, confirming the involvement of interface 1 and 2 in the interaction with $\mathrm{M} 2 \mathrm{e}$. These findings are also in line with the observation that $\mathrm{M} 2 \mathrm{e}-\mathrm{VHH}-23 \mathrm{~m}$ fails to bind the $\mathrm{H} 1 \mathrm{~N} 1$ A/Brevig Mission/1/1918 M2e peptide, which carries a serine instead of an isoleucine residue at position 11 (Figure 1B). Reduced binding to cells expressing M2Val7Ala also concurs 
A

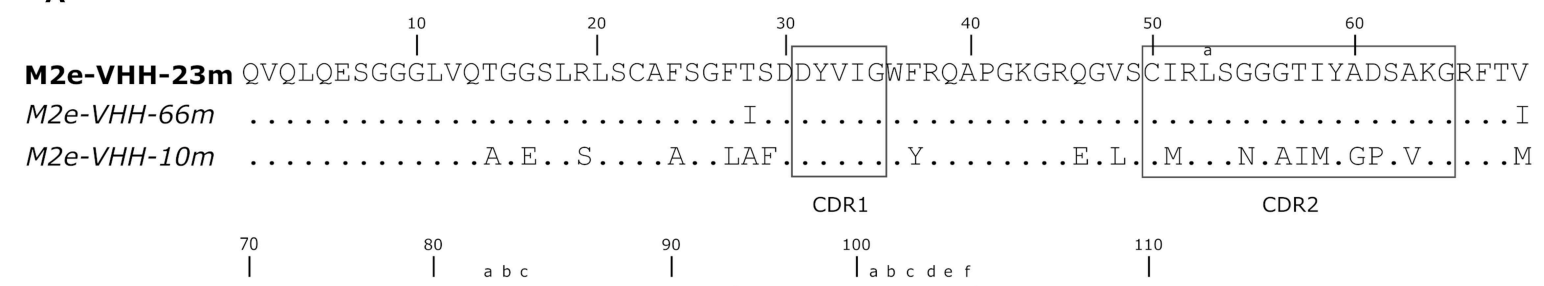

M2e-VHH-23m SADNAKKTVYLQMTRLKPEDTAVYYCGAERYNVEGCGYDVAYWGKGTQVTVSS

M2e-VHH-66m

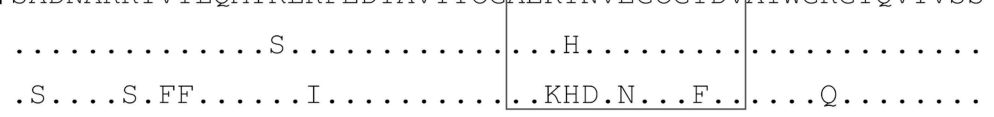

M2e-VHH-10m

CDR3

M2e-tGCN4

SLLTEVETPIRNEWGCRCNDSSGG LKQIEDKLEEILSKLYHIENELARIKKLLGE

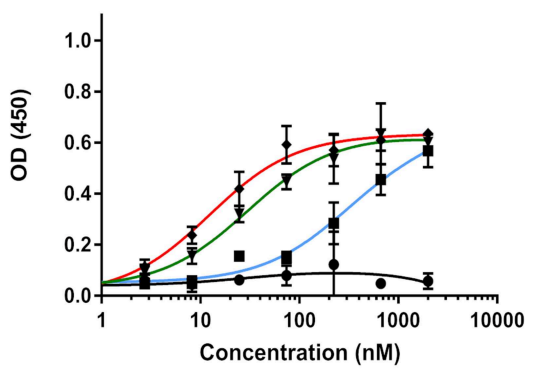

M2e peptide (H3N2)

SLLTEVETPIRNEWGCRCNDSSDSG

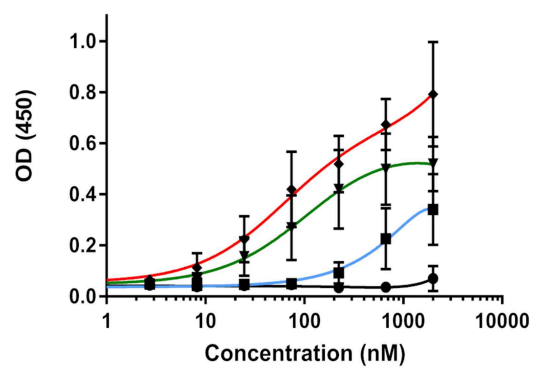

A/swine/Belgium/1/1998 (H1N1)

SLLTEVETPTRNGWECRYSGSSDSG

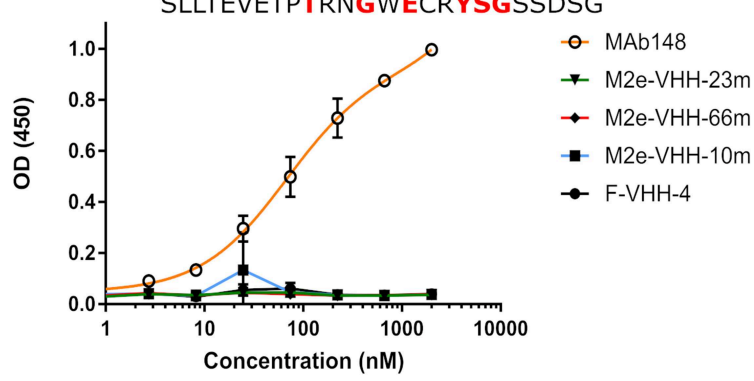

BM2e-tGCN4

LEPFGG

LKQIEDKLEEILSKLYHIENELARIKKLLGE

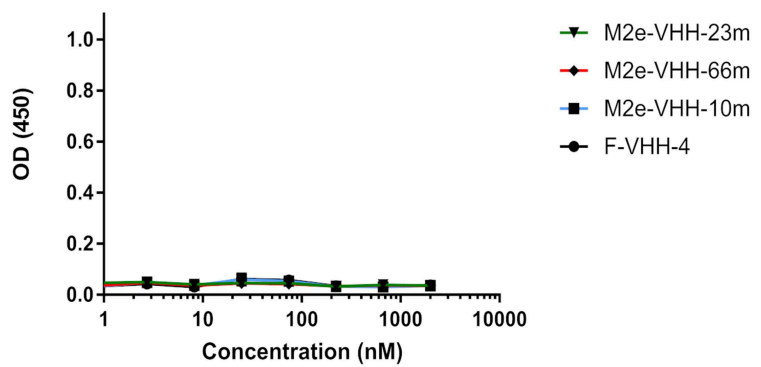

A/Brevig Mission/1/1918 (H1N1)

SLLTEVETPTRNEWGCRCNDSSDSG

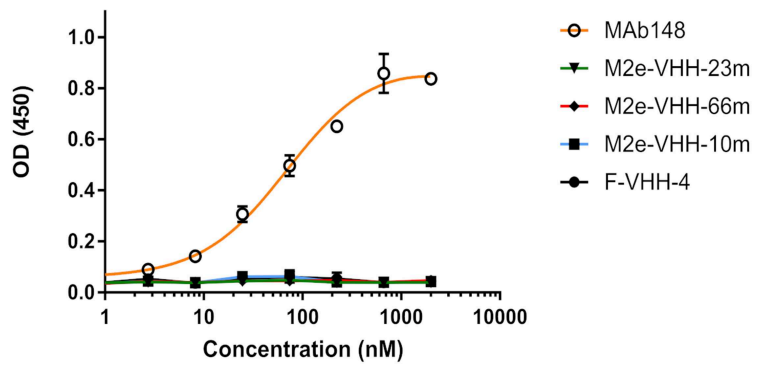

A/Hong Kong/485/1997 (H5N1)

SLLTEVETLTRNGWGCRCSDSSDSG

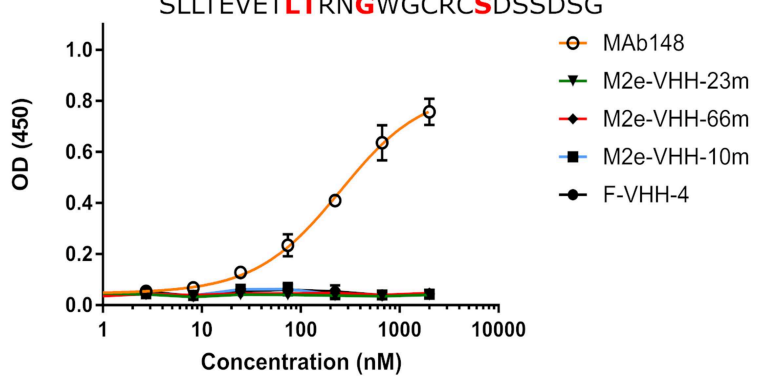

FIGURE 1 | M2e-specific VHHs and their binding specificities. (A) Predicted amino acid residue sequences of M2e-VHH-23m and M2e-VHH-66m (isolated after panning on M2e-tGCN4 and human H3N2 M2e peptide) and M2e-VHH-10m (isolated after panning on HEK cells stably expressing M2). Above the sequences the 
FIGURE 1 | Kabat numbering is indicated. The complementarity determining regions (CDR) are boxed. (B) M2e peptide ELISAs. Wells of microtiter plates were coated with $100 \mathrm{ng} \mathrm{M2e-tGCN4,} \mathrm{BM2e-tGCN4,} \mathrm{or} \mathrm{high-performance} \mathrm{liquid} \mathrm{chromatography} \mathrm{(HPLC)-purified} \mathrm{M2e} \mathrm{peptide.} \mathrm{The} \mathrm{amino} \mathrm{acid} \mathrm{residue} \mathrm{sequences} \mathrm{of} \mathrm{the}$ coated proteins or peptides are depicted above the graphs. Amino acid residues that deviate from the consensus human $\mathrm{H} 3 \mathrm{~N} 2 \mathrm{M} 2 \mathrm{e}$ sequence are highlighted in red. Dilution series of the indicated VHHs and MAb148 (a mouse monoclonal lgG1 that recognizes the M2e N-terminus) were added to the coated plates. Binding was detected with a mouse anti-His tag MAb, followed by a secondary sheep anti-mouse IgG Ab conjugated to horseradish peroxidase (HRP). Data points represent averages of triplicates and error bars represent standard deviations.

with the co-crystal structure data which show an interaction of M2eVal7 with a shallow hydrophobic pocket on the surface of M1e- VHH-23m (Figure 3A).

\section{M2e-VHH-23m Binds to Infected Cells and Does Not Neutralize Influenza A Virus}

Next we used flow cytometry to determine if M2e-VHH$\mathrm{m} 23$ could bind to M2e in its natural context, on the surface of influenza A virus infected cells. HEK293T cells were infected with A/Puerto Rico/8/1934 (H1N1) (M2e: SLLTEVETPIRNEWGCRCNGSSD), A/X47 (H3N2) (M2e: SLLTEVETPIRNEWGCRCNDSSD) or A/Udorn/307/1972 (H3N2) (M2e: SLLTEVETPIRNEWGCRCNDSSD) and were subsequently immuno-stained with MAb148, M2e-VHH-23m or F-VHH-4. M2e-VHH-23m could bind to the surface of cells infected with either of the three viruses with a $K_{d}$ of $13.63 \mathrm{nM}$ for influenza A/Puerto Rico/8/1934 (H1N1) infected cells (Figure 4A). In contrast, and as expected, M2e-VHH-23m failed to bind to cells infected with A/Swine/Ontario/42729A/2001 (H3N3) (M2e: SLLTEVETPTRNGWECRCSDSSD) virus. These data confirm that M2e-VHH-23m can bind to M2e sequences that are similar to the H3N2 M2e consensus sequence, recognizes the central part of such M2e sequences and that at least the aspartic acid to glycine substitution at position 21 in A/Puerto Rico/8/1934 M2 is not essential for binding.

It is known that some anti-M2e antibodies can restrict the in vitro replication of certain influenza A virus strains such as $\mathrm{A} / \mathrm{Udorn} / 307 / 1972$ and $\mathrm{A} /$ Hong Kong/8/1968 but not other viruses such as A/Puerto Rico/8/1934 and A/WSN/1933 in vitro $(54,55)$. To address this issue, M2e-VHH-23m or MAb37, a M2especific IgG1 antibody with in vitro neutralizing activity against A/Udorn/307/1972, were mixed with 10-20 plaque forming units (pfu) of A/Puerto Rico/8/1934 or A/Udorn/307/1972 before infection of MDCK cells (56). As expected, both the plaque size and number of A/Udorn/307/1972, but not of A/Puerto Rico/8/1934 were reduced in the presence of MAb37 (Figure 4B). However, unlike MAb37, and even at a concentration of $2.5 \mu \mathrm{M}$ $(30 \mu \mathrm{g} / \mathrm{ml}), \mathrm{M} 2 \mathrm{e}-\mathrm{VHH}-23 \mathrm{~m}$ did not affect the number and size of A/Udorn/307/1972 plaques (Figure 4B).

\section{Isolation of FcyRIV-Specific VHHs}

Our next aim was to arm M2e-VHH-23m with a second $\mathrm{VHH}$ that targets one of the activating Fc $\gamma$ Rs such as Fc $\gamma$ RIV. We focused on this activating Fc $\gamma$ R because of its restricted expression on macrophages, monocytes, neutrophils and dendritic cells but no other myeloid cell population, and because of its very high affinity for IgG2a monoclonal antibodies, which contribute the most protection by non-neutralizing influenza antibodies in the mouse model $(13,20)$.
To isolate Fc $\gamma$ RIV-specific VHHs a phage library obtained from a llama that had been immunized with immature mouse dendritic cells (described by Deschacht et al.) was enriched for candidate Fc $\gamma$ RIV-specific phagemid clones by three panning rounds using immobilized recombinant mouse Fc $\gamma$ RIV extracellular domain protein produced in HEK293T cells (32). Of these candidates, Fc $\gamma$ RIV-VHH-7m was selected after a subsequent ELISA screen using the Fc $\gamma$ RIV antigen (Figure 5A). The binding specificity of purified Fc $\gamma$ RIV-VHH-7m was analyzed by flow cytometry using HEK-293 cells that were transiently transfected with GFP and expression vectors coding for mouse Fc $\gamma$ RI, Fc $\gamma$ RIII or Fc $\gamma$ RIV together with a plasmid coding for the common $\gamma$-chain, or with an expression vector coding for the inhibitory Fc $\gamma$ RIIb. Concentration-dependent binding to cells transfected with the mouse Fc $\gamma$ RIV plus the common $\gamma$ chain was clearly detected (Figure 5B). Only at the highest concentration tested, Fc $\gamma$ RIV-VHH-7m weakly bound to HEK293T cells that expressed mouse Fc $\gamma$ RI, Fc $\gamma$ RIIb or Fc $\gamma$ RIII (Figure 5B). Expression of the Fc $\gamma$ Rs on the surface of the HEK293T cells was verified by staining with an antibody directed against the tag attached to the Fc $\gamma$ Rs (Figure S4). Clear expression of the mouse Fc $\gamma$ RI, Fc $\gamma$ RIII and Fc $\gamma$ RIV was detected. Expression of the mouse Fc $\gamma$ RIIb was less evident, therefore no firm conclusions about the binding of Fc $\gamma$ RIVVHH-7m to the mouse Fc $\gamma$ RIIb could be deduced. To evaluate that Fc $\gamma$ RIV-VHH-7m was able to bind to cells that express endogenous levels of the mouse Fc $\gamma$ RIV, we tested its binding to Mf4/4 cells, a mouse macrophage like cell line (29). Unlike M2eVHH-M2e, Fc $\gamma$ RIV-VHH-7m bound Mf $4 / 4$ cells with a deduced $K_{d}$ value comparable to the $K_{d}$ value for binding to $F c \gamma R I V$ transfected cells (Figure 5B).

\section{Tail-to-Head Fused Fc $\gamma$ RIV- and M2e-Specific VHHs Selectively and M2-Dependently Activate Fc $\gamma$ RIV}

To evaluate the possibility to arm the M2e-specifc VHH with Fc $\gamma$ RIV-dependent effector functions, we genetically fused M2eVHH-23m carboxy-terminal of Fc $\gamma$ RIV-VHH-7m by means of a flexible 15 amino acid long $\left(\mathrm{Gly}_{4} \mathrm{Ser}\right)_{3}$ linker. As controls M2e-VHH-23m was also fused to a VHH directed against human Fc $\gamma$ RIIIa [described by Behar et al. (48)] and Fc $\gamma$ RIVVHH-7m was linked to F-VHH4. The resulting constructs were named Fc $\gamma$ RIV VHH-M2e VHH, Fc $\gamma$ RIIIa VHH-M2e VHH, and Fc $\gamma$ RIV VHH-F VHH, respectively, and were produced in transformed Pichia pastoris shake flask cultures (Figure 6A). Fc $\gamma$ RIV VHH-M2e VHH could bind to M2e peptide and coated soluble Fc $\gamma$ RIV protein in ELISA (Figure 6A). Next, we evaluated the potency of the bispecific constructs to activate individual 


\section{A/consensus human H3N2}

\section{SLLTEVETPIRNEWGCRCNDSSDSG}

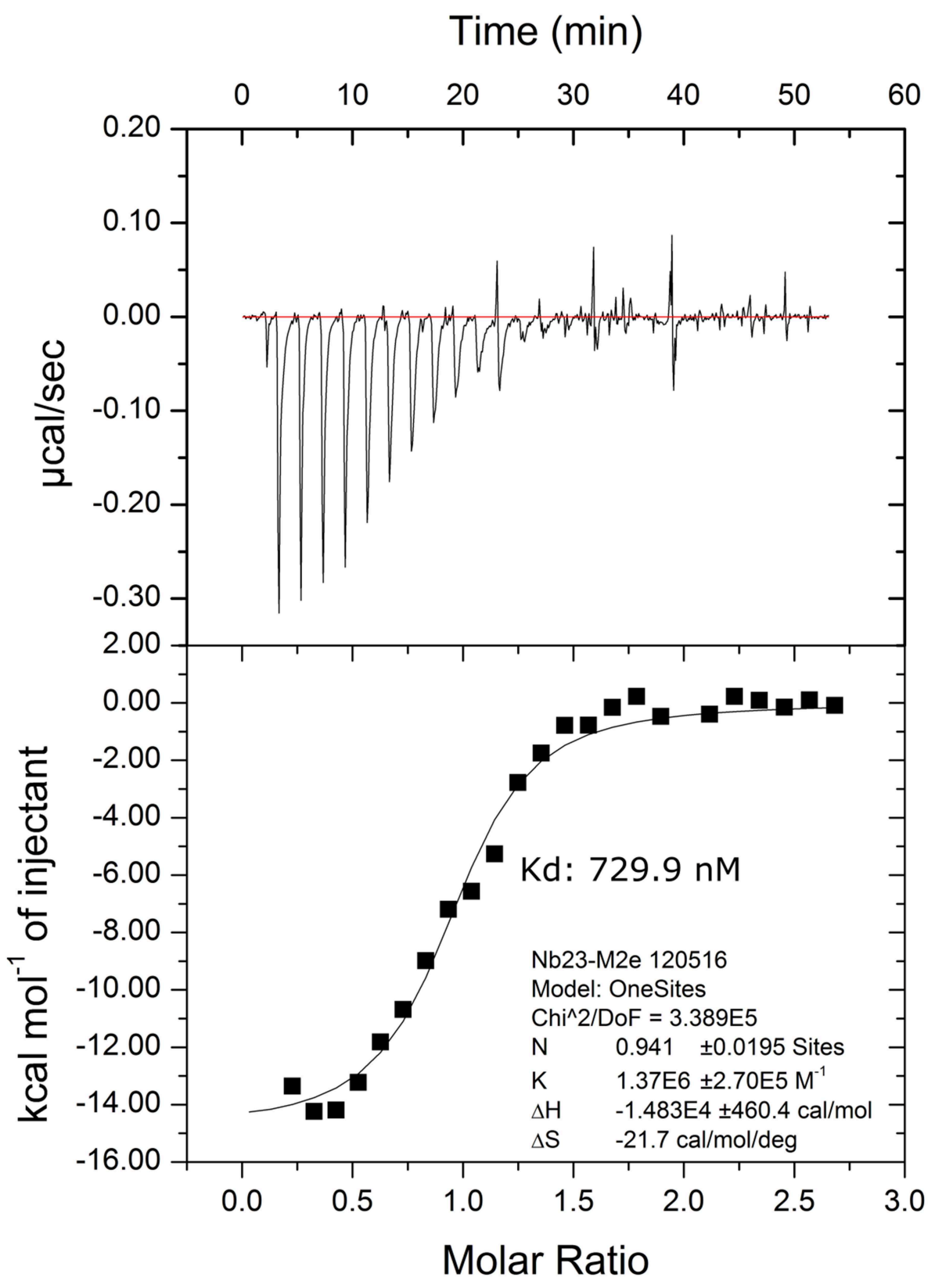

FIGURE 2 | Thermodynamic characterization of the M2e:M2e-VHH-23m interaction. Isothermal titration calorimetry of the Me peptide into M2e-VHH-23m.

Fc $\gamma$ Rs in vitro, by making use of a co-culture of M2-expressing cells and a set of reporter cell transfectants, which produce interleukin 2 upon the activation of a specific Fc $\gamma \mathrm{R}$ (Figure 6B) (30). As controls for $F c \gamma R$ activation, we used mouse M2especific MAb 37 (IgG1) and MAb 65 (IgG2a). In the presence of M2-expressing HEK293T cells, MAb 65 dose-dependently activated all mouse FcyRs. This is expected as mouse IgG2a antibodies can bind and activate all mouse Fc $\gamma$ Rs (16). Only mouse Fc $\gamma$ RIIb and -RIII were activated by MAb37, again in line with the known binding specificity of mouse IgG1 antibodies for mouse FcyRs (15). In the presence of M2-expressing cells Fc $\gamma$ RIV VHH-M2eVHH potently activated mouse Fc $\gamma$ RIV but 

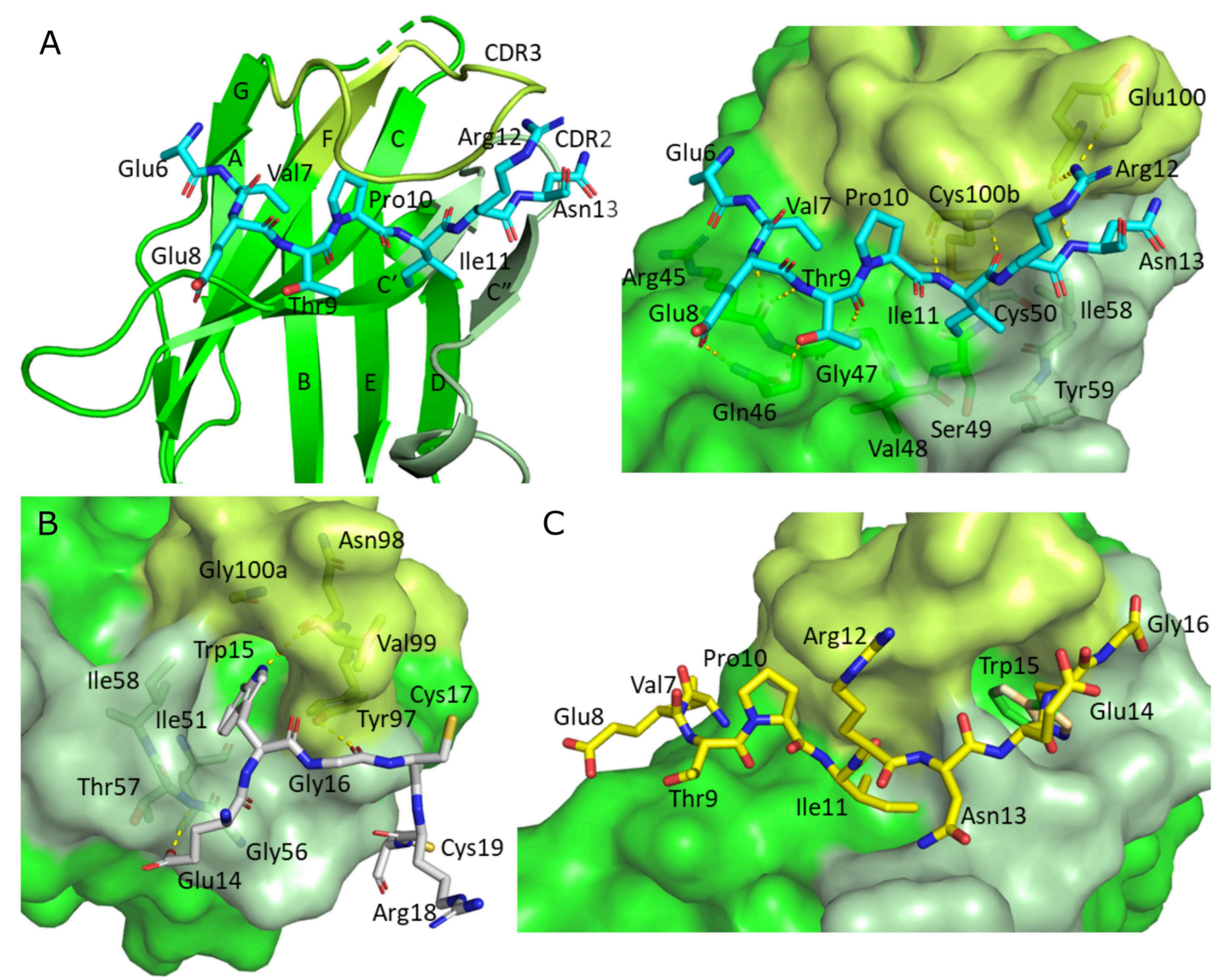

D

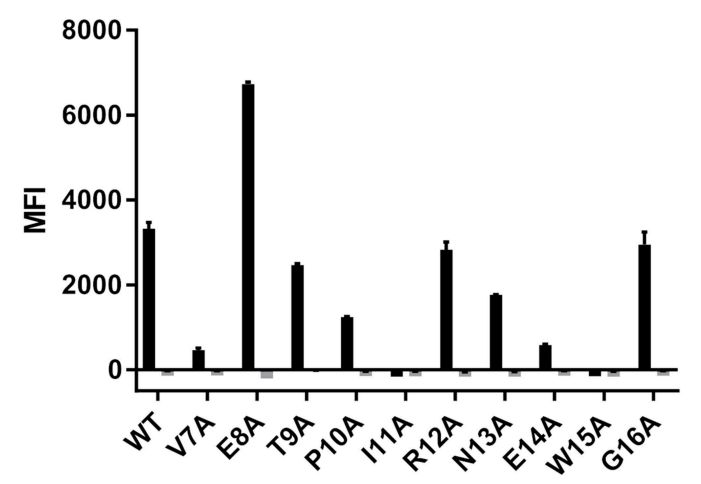

M2e-VHH-23m
F-VHH-4

FIGURE 3 | Molecular details of the M2e-VHH-23m: M2e interaction. (A) Crystal structure of M2e-VHH-23m in complex with the M2e peptide, showing the linear binding epitope of M2e residues 6-13 binding to a shallow groove on the surface of M2e-VHH-23m (Interface 1). Left: The M2e peptide is shown in cyan stick representation, the $\mathrm{M} 2 \mathrm{e}-\mathrm{VHH}-23 \mathrm{~m}$ in green cartoon representation. CDR2 and CDR3 are colored pale and lime green, respectively. Right: Details of the interactions between M2e residues 6-13 and the residues making up interface 1 on M2e-VHH-23m. (B) Details of the interactions between M2e residues 14-19 and the residues making up interface 2 on $\mathrm{M} 2 \mathrm{e}-\mathrm{VHH}-23 \mathrm{~m}$. Coloring of $\mathrm{M} 2 \mathrm{e}-\mathrm{VHH}-23 \mathrm{~m}$ as in $\mathrm{A}, \mathrm{M} 2 \mathrm{e}$ shown in gray stick representation. (C) Docking of the M2e peptide on the crystal structure of $\mathrm{M} 2 \mathrm{e}-\mathrm{VHH}-23 \mathrm{~m}$ confirms the ligand swapping hypothesis, showing that $\mathrm{M} 2 \mathrm{e}$ binds an extended grove on $\mathrm{M} 2 \mathrm{e}-\mathrm{VHH}-23 \mathrm{~m}$ comprising both Interface 1 and Interface 2. Coloring of M2e-VHH-23m as in A, M2e shown in yellow stick representation. (D) Binding of M2e-VHH-23m to M2e Ala scan mutants. HEK293T cells were transfected with Flag-tagged M2 wild type (WT) and M2e Ala scan mutant expression constructs and subsequently incubated with $20 \mu \mathrm{g} / \mathrm{ml}$ of M2e-VHH-23m or F-VHH-4. After fixation with $2 \%$ paraformaldehyde and permeabilization, binding was detected with a mouse anti-Histidine tag antibody and rabbit anti-Fag tag antibody followed by an anti-mouse IgG Alexa 647 and anti-rabbit IgG Alexa 488, respectively. The median fluorescence intensity (MFI) was calculated by subtracting the median fluorescence of binding of $\mathrm{M} 2 \mathrm{e}-\mathrm{VHH}-23 \mathrm{~m}$ or $\mathrm{F}-\mathrm{VHH}-4$ to transfected cells from the median fluorescence of non-transfected cells bound by $\mathrm{M} 2 \mathrm{e}-\mathrm{VHH}-23 \mathrm{~m}$ or $\mathrm{F}-\mathrm{VHH}-4$. 
A

A/PR/8/1934 (H1N1)

SLLTEVETPIRNEWGCRCNGSSD

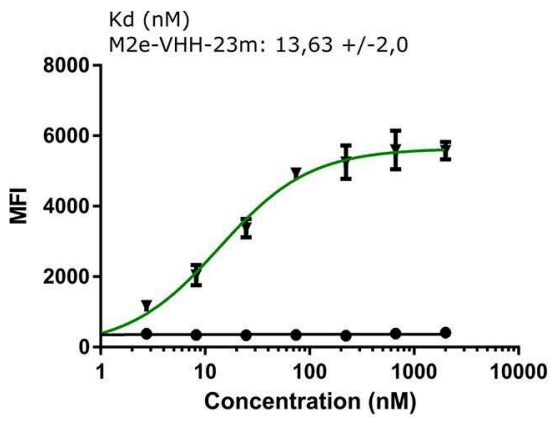

A/Udorn/307/1972 (H3N2)

SLLTEVETPIRNEWGCRCNDSSD

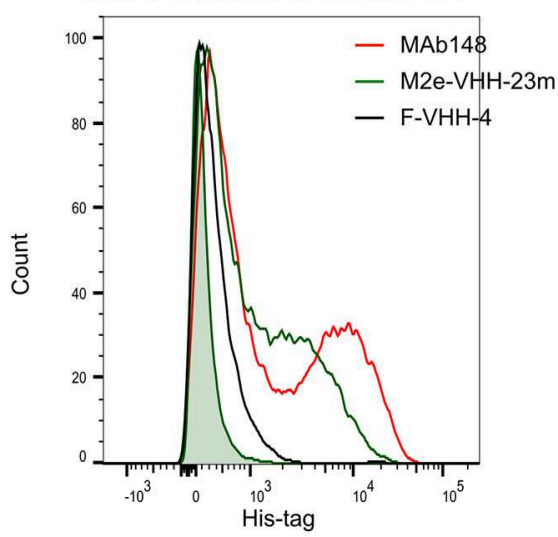

B

\section{A/Udorn/307/1972 (H3N2)}

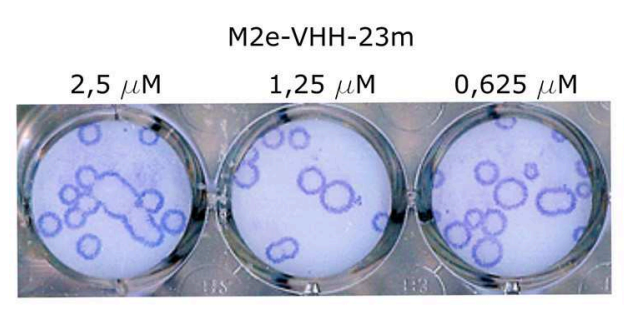

$\mathrm{mAb} 37$

$0,333 \mu \mathrm{M}$

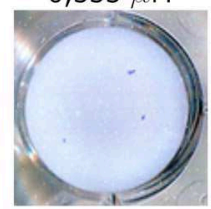

A/PR/8/1934 (H1N1)

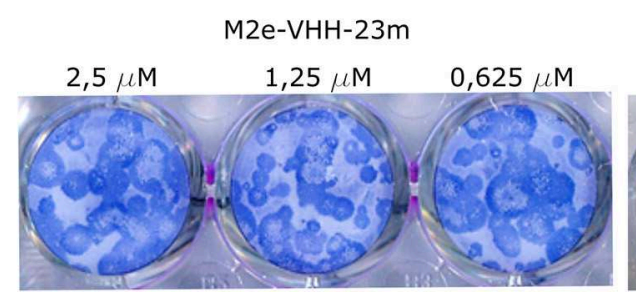

₹ $\mathrm{M} 2 \mathrm{e}-\mathrm{VHH}-23 \mathrm{~m}$

- $\mathrm{F}-\mathrm{VHH}-4$

A/Swine/Ontario (H3N3)

SLLTEVETPTRNGWECRCSDSSD

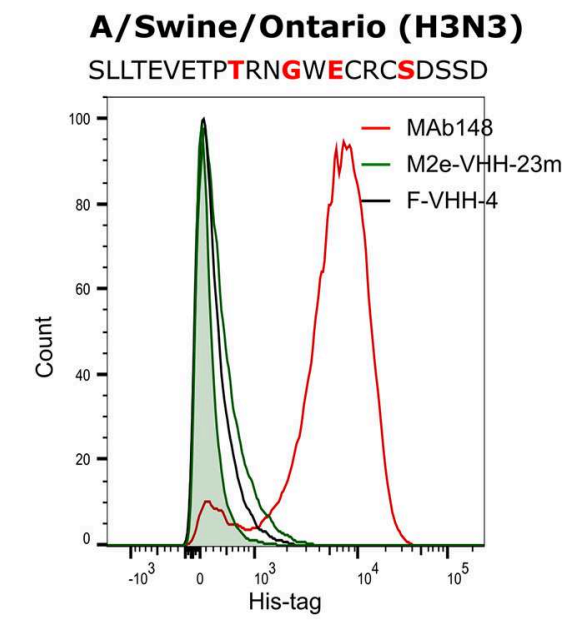

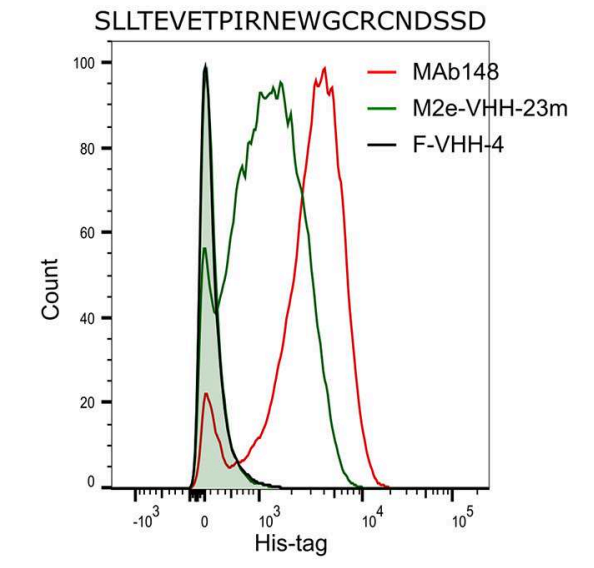




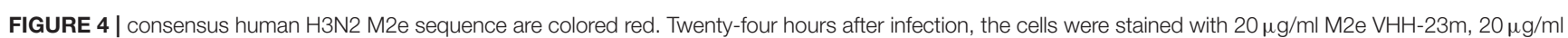
$\mathrm{F}-\mathrm{VHH}-4$ or $10 \mu \mathrm{g} / \mathrm{ml}$ MAb148. The A/Puerto Rico/8/1934 (H1N1) infected cells were stained with 1/3 dilution series of M2e-VHH-23m or F-VHH-4. After fixation with $2 \%$ paraformaldehyde, infected cells were stained with goat anti-A/Puerto Rico/8/1934 serum followed by anti-goat IgG Alexa 647 and bound VHHs were detected with a mouse anti-Histidine tag antibody followed by anti-mouse IgG Alexa 488. The mean fluorescence intensity (MFI) was calculated by subtracting the median fluorescence of binding of $\mathrm{M} 2 \mathrm{e}-\mathrm{VHH}-23 \mathrm{~m}$ or $\mathrm{F}-\mathrm{VHH}-4$ to infected cells from the median fluorescence of uninfected cells bound by $\mathrm{M} 2 \mathrm{e}-\mathrm{VHH}-23 \mathrm{~m}$ or $\mathrm{F}-\mathrm{VHH}-4$. Data points represent averages of triplicates and error bars represent standard deviations. Results of a representative of 3 repeat experiments is depicted for the binding to the A/Puerto Rico/8/1934 ( $\mathrm{H} 1 \mathrm{~N} 1$ ) infected cells, the dissociation constant (Kd), is the average of three independent experiments together with the standard deviation. The green shading in the histograms corresponds to the binding of M2e-VHH-23m to mock-infected HEK cells. (B) M2e-VHH-23m $(2.5,1.25$, or $0.625 \mu \mathrm{M})$, $0.333 \mu \mathrm{M}$ MAb37 or sera of mice infected with A/Puerto Rico/8/1934 (H1N1) virus were incubated with 10 to 20 plaque forming units/well of A/Udorn/307/1972 (H3N2) or A/Puerto Rico/8/1934 (H1N1) virus and then added to MDCK cells. After $1 \mathrm{~h}$, the cells were overlaid with Avicel supplemented with TPCK-treated trypsin. The overlay was removed after 2 days, cells were fixed with paraformaldehyde and viral plaques were stained with convalescent mouse anti- A/Puerto Rico/8/1934 or A/Udorn/307/1972 serum followed by HRP-linked anti-mouse IgG (NXA931, GE Healthcare) and TrueBleu substrate.

not Fc $\gamma$ RI, -III, and -IIb. None of the control VHH fusion constructs activated any of the Fc $\gamma$ Rs, indicating that specificity for both M2e and Fc $\gamma$ RIV of the VHH fusion constructs was required. Moreover, activation of the mouse Fc $\gamma$ RIV reporter cells by Fc $\gamma$ RIV VHH-M2eVHH was only observed in the presence of M2 expressing target cells (Figure S5). Potent and dose-dependent activation of mouse Fc $\gamma$ RIV by the Fc $\gamma$ RIV VHH-M2e VHH fusion was also observed when A/Puerto Rico/8/1934 infected MDCK cells were used as target cells (Figure 6C). Finally, Fc $\gamma$ RIIIa VHH-M2e VHH, but not Fc $\gamma$ RIV VHH-M2eVHH, activated the human Fc $\gamma$ RIIIa, the ortholog of mouse Fc $\gamma$ RIV, in the presence of A/Puerto Rico/8/1934 infected targeted cells (Figure 6D). We conclude that the tail-tohead fusion of the Fc $\gamma$ RIV- with the M2e-specific VHHs allows selective, M2-dependent in vitro activation of the mouse Fc $\gamma$ RIV.

\section{Intranasal Administration of Bispecific Fc $\gamma$ RIV VHH-M2e VHH Protects Mice From a Potentially Lethal Influenza A Virus Challenge}

In a final set of experiments, we explored the protective potential of Fc $\gamma$ RIV VHH-M2e VHH in vivo. SPF-housed female BALB/c mice were treated intranasally with $50 \mu \mathrm{g}$ Fc $\gamma$ RIV VHH-M2e $\mathrm{VHH} 4 \mathrm{~h}$ before and $24 \mathrm{~h}$ after challenge with $2 \mathrm{xLD}_{50}$ of $\mathrm{A} / \mathrm{X} 47$ (H3N2) influenza virus. As controls, mice were treated with PBS, $50 \mu \mathrm{g}$ of Fc $\gamma$ RIIIa VHH-M2e VHH or Fc $\gamma$ RIV VHH-F VHH. The mice that had been treated with Fc $\gamma$ RIV VHH-M2e VHH were significantly better protected from body weight loss and lethality caused by the influenza virus infection compared, to mice that had been treated with the negative control VHH fusion constructs, which combine targeting of Fc $\gamma$ RIIIa with M2e-specificity or targeting of RSV-F with Fc $\gamma$ RIII-specificity (Figure 7A). In addition, the protection mediated by Fc $\gamma$ RIV VHH-M2e VHH was associated with a modest but statistically significant reduction in lung viral titer (Figure 7B). To verify if the protection by Fc $\gamma$ RIV VHH-M2e VHH was mediated by Fc $\gamma$ RIV engagement, wild-type and $F c \gamma R I V^{-/-} \mathrm{C} 57 \mathrm{BL} / 6$ mice were intranasally treated with $50 \mu \mathrm{g}$ Fc $\gamma$ RIV VHH-M2e VHH or Fc $\gamma$ RIIIa VHH-M2e VHH, as negative control, $4 \mathrm{~h}$ before and $24 \mathrm{~h}$ after challenge with $2 \mathrm{XLD}_{50}$ of $\mathrm{A} / \mathrm{X} 47$ ( $\left.\mathrm{H} 3 \mathrm{~N} 2\right)$ influenza virus. While treatment with Fc $\gamma$ RIV VHH-M2e VHH could protect wild-type mice, $F c \gamma R I V^{-/-}$mice and control-treated wild-type mice did not survive the virus challenge (Figure 7C).
Moreover, body weight loss after challenge was statistically significantly reduced in Fc $\gamma$ RIV VHH-M2e VHH treated wildtype mice, compared to $F c \gamma R I V^{-/-}$mice $(p<0.001)$. Thus, selective targeting of mouse Fc $\gamma$ RIV with the recombinant twodomain construct Fc $\gamma$ RIV VHH-M2e VHH, can protect mice against a potentially lethal influenza $\mathrm{A}$ virus challenge.

\section{DISCUSSION}

Formatting of VHH fragments to develop biologicals to prevent or treat infectious diseases is a powerful and attractive approach to develop biologicals with enhanced specificity, activity, halflife and breadth of protection. Here, VHH formatting was used to test if arming of a virus surface antigen-specific VHH with an artificial and selective $\mathrm{F} c \gamma \mathrm{R}$ activation function can potentiate its activity to combat viral infections in the absence of direct virus neutralization. To explore this possibility, we focused on influenza A M2e as a viral target. This antigen is conserved among influenza $\mathrm{A}$ viruses and is therefore an attractive target to achieve broad protection. M2e-specific VHHs were obtained after immunization of a llama with M2e fused to a heterologous tetramerizing domain, to mimic the natural quaternary structure of M2, followed by panning on M2e peptide or cells that stably express M2. We isolated and characterized in more detail three M2e-specific VHHs. Although several M2especific conventional MAbs have been described in recent years, to our knowledge, these are the first reported single domain antibodies that specifically bind to M2e. Recently, a M2-specific VHH was isolated from a synthetic VHH library by Wei et al. (57), however their VHH failed to bind to M2e peptide.

We determined the crystal structure of $\mathrm{M} 2 \mathrm{e}-\mathrm{VHH}-23 \mathrm{~m}$ in complex with a M2e peptide, that corresponds to the consensus sequence of human H1N1 viruses that circulated between 1933 and 2008, human H2N2 and H3N2 viruses. This structure revealed that the M2e antigen is bound by the VHH in an extended conformation that wraps around two main interfaces on the VHH. A first interface is a shallow groove formed by the CDR2 and CDR3 loops and the C, C, C", and F $\beta$-strands (Figure 3A). This interface binds the M2e region spanning residues 6-12, where Val7, Pro10 and Ile 11 bind hydrophobic patches on the VHH. In addition to three main chain interactions, the side chains of M2eGlu8 and -Thr9 each go into an H-bond interaction with the VHH. A second binding interface is found on the "back" side of the $\mathrm{VHH}$, interacting with 
A

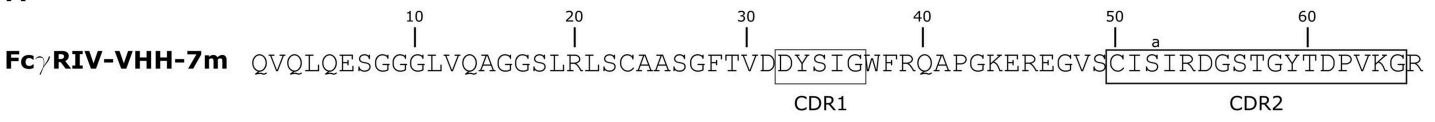

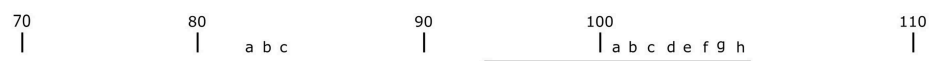

Fc $\gamma$ RIV-VHH-7m FTISSDNAKNMVYLQMNMLKPEDTAVYYCA GDIYCSNDDVGVGPYDYWGQGTQVTVSS

B
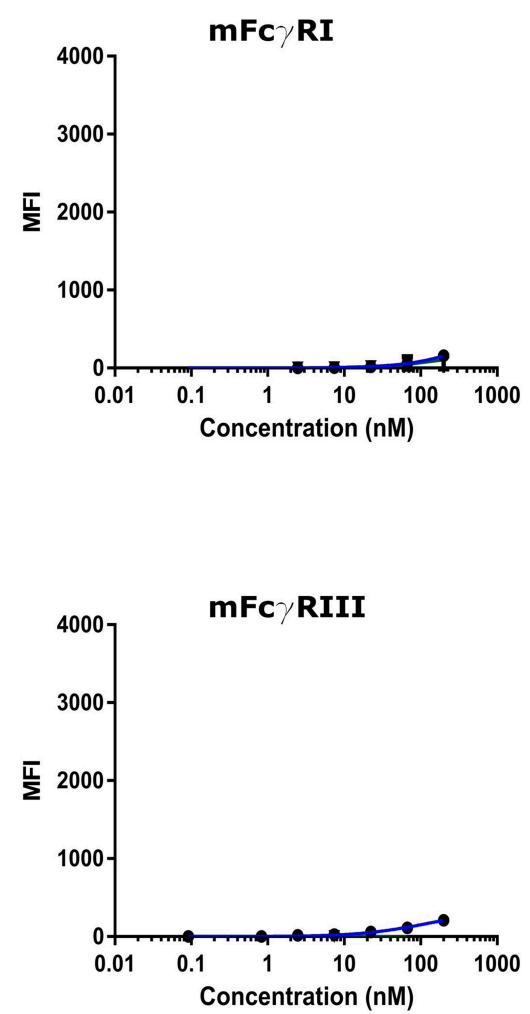

CDR3
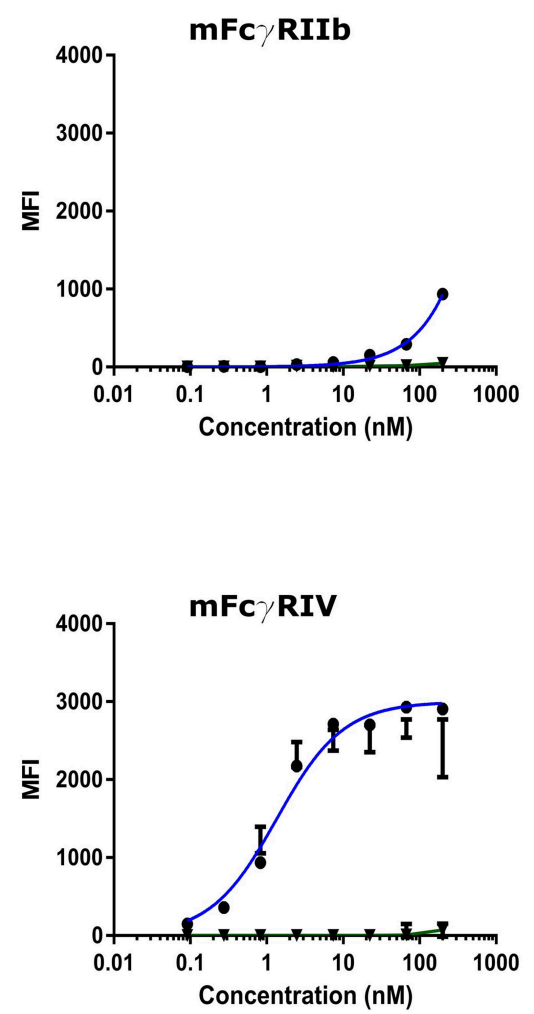

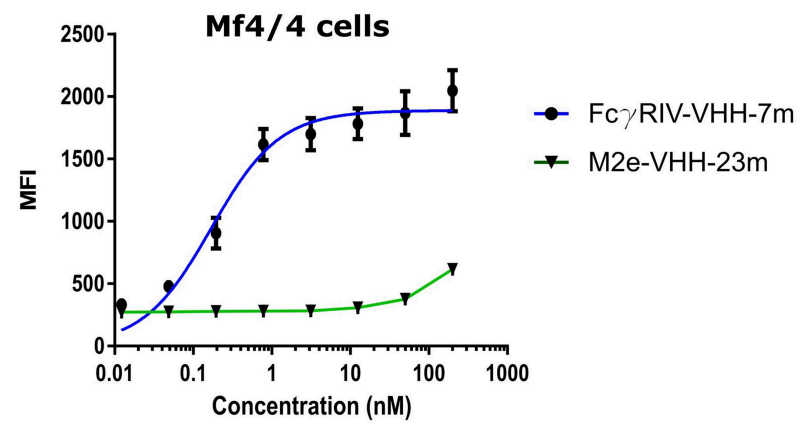

FIGURE 5 | Characterization of the isolated Fc $\gamma R$ RIV-specific VHH. (A) The predicted amino acid residue sequence of Fc $\gamma$ RIV-VHH-7m, isolated after panning on recombinant mouse Fc $\gamma R$ IV protein of a VHH library derived from a llama immunized with immature mouse dendritic cells. Above the sequences the Kabat numbering is indicated. CDR1, -2 , and -3 are boxed. (B) Flow cytometric analysis showing binding of FcgRIV-VHH-7m and M2e-VHH-23m to HEK 293T cells transiently transfected with expression vectors coding for mouse Fc $\gamma R I$, F $\gamma$ RIllb, Fc $\gamma$ RIII, and Fc $\gamma R I V$ along with the common $\gamma$-chain for the activating Fc $\gamma$ Rs and a GFP expression plasmid. The lower graph depicts binding to Mf4/4 cells. The cells were incubated with fourfold serial dilution of Alexa Fluor ${ }^{\mathrm{TM}} 647$ labeled Fc $\gamma \mathrm{RIV}-\mathrm{VHH}-7 \mathrm{~m}$ or $\mathrm{M} 2 \mathrm{e}-\mathrm{VHH}-23 \mathrm{~m}$, starting at a concentration of $0.2 \mu \mathrm{M}$, binding of the VHHs to the GFP positive cells was analyzed. Data points represent averages of triplicates and error bars standard deviations. 
A

M2e peptide (H3N2)

SLLTEVETPIRNEWGCRCNDSSDSG

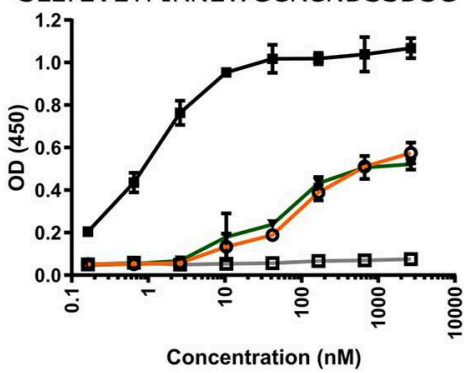

B

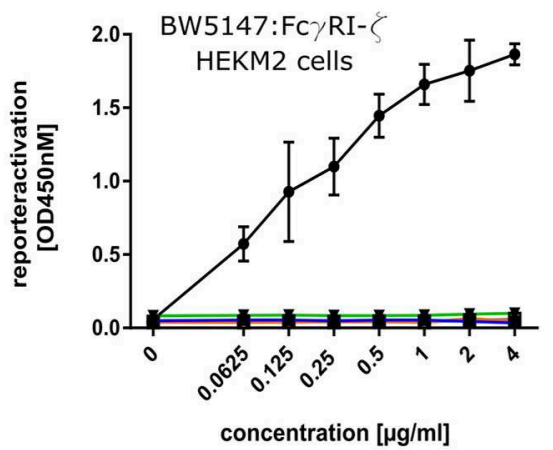

BW5147:Fc $\gamma$ RIII- $\zeta$

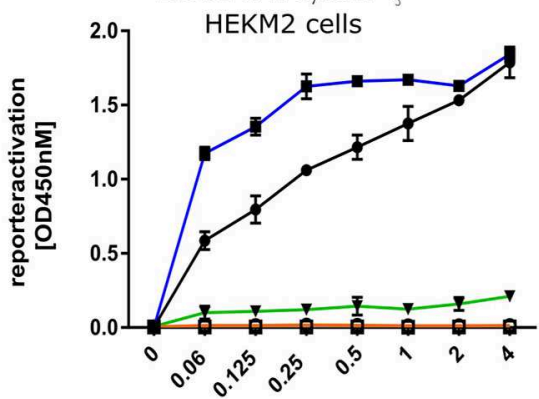

concentration $[\mu \mathrm{g} / \mathrm{ml}]$

C

BW5147:FC $\gamma$ RIV- $\zeta$

A/PR/8/1934 (H1N1)

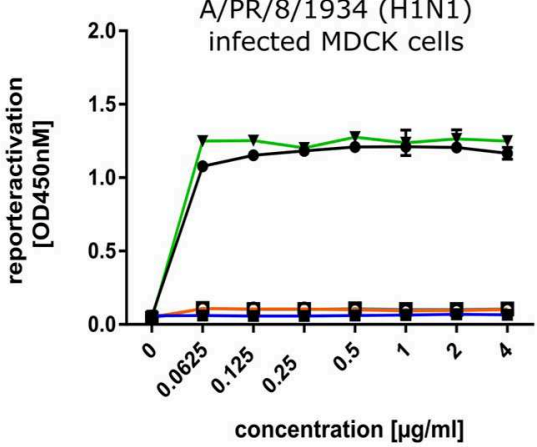

FC $\gamma$ RIV protein
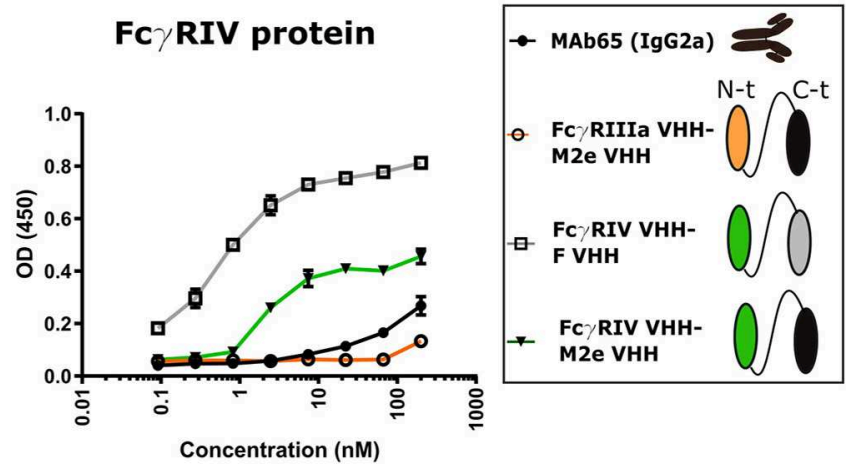

Concentration (nM)

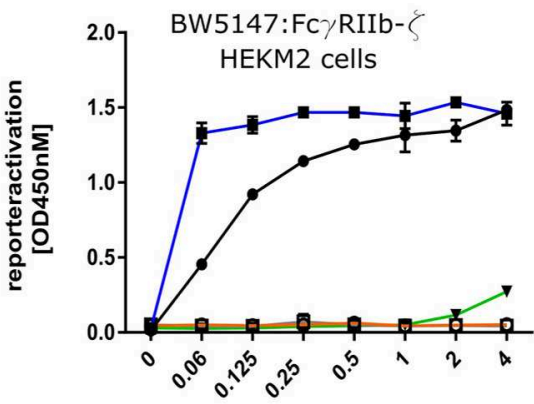

concentration $[\mu \mathrm{g} / \mathrm{ml}]$

BW5147:Fc $\gamma$ RIV- $\zeta$

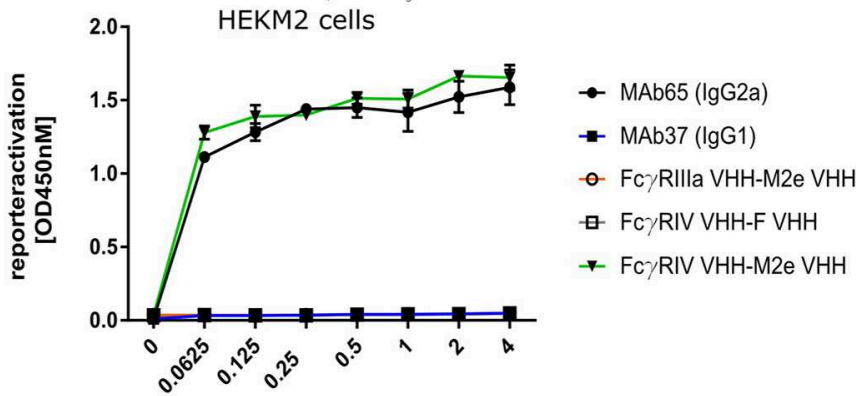

concentration $[\mu \mathrm{g} / \mathrm{ml}]$

D

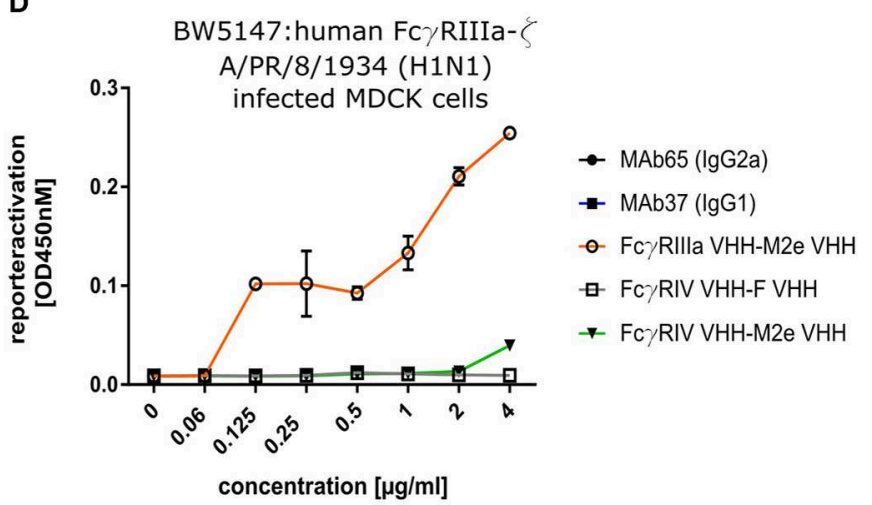

FIGURE 6 | Bispecific fusion construct of anti-mouse FcyRIV VHH with M2e-VHH-23m selectively activates FcyRIV in vitro. (A) Schematic representation of the bispecific VHHs and ELISA on human H3N2 M2e peptide and recombinant FcyRIV protein is shown on the right. Wells of microtiter plates were coated with 100 ng 
FIGURE 6 | peptide or protein. Dilution series of the bispecific VHH fusion constructs were added to the coated plates. Binding was detected with a mouse anti-His tag MAb, followed by a secondary sheep anti-mouse IgG Ab conjugated to HRP for the peptide ELISA. In the ELISA with coated recombinant Fc $\gamma R$ IV protein, binding was detected with a HRP-conjugated rabbit anti-camelid VHH antibody. (B) Serial dilutions of the bispecific VHH fusion construct or monoclonal antibodies were added to HEK293T cells stably transfected with an influenza M2 expression plasmid. Thirty minutes later, FC $\gamma$ R- $\zeta$ BW5147 reporter cells were added to the HEK293T cells. After overnight incubation produced mIL-2 was measured in a sandwich-ELISA, which served as an indicator for the magnitude of FC $\gamma \mathrm{R}$ activation. (C) MDCK cells were infected with A/Puerto Rico/8/1934 (H1N1) virus for $1 \mathrm{~h}$. Unbound virus particles were washed away and serial dilutions of the bispecific VHHs or monoclonal antibodies were added and incubated for 30 min, followed by the addition of the Fc $\gamma$ RIV- $\zeta$ BW5147 reporter cells (C) or human Fc $\gamma$ RIIla- $\zeta$ BW5147 reporter cells (D). After overnight incubation supernatants were analyzed by an anti mIL-2 sandwich ELISA. Data points represent averages of triplicates and error bars represent standard deviations. The graphs are a representative of one out of three repeat experiments.

residues $14-19$ of $\mathrm{M} 2 \mathrm{e}$. This interface contains a well-defined hydrophobic pocket that captures the side chain of the highly conserved Trp15. Most avian and swine influenza A viruses, and, since the 2009 pandemic, also most circulating human H1N1 viruses, have a threonine instead of an isoleucine at position 11 of M2(e). Threonine is not hydrophobic and would be incompatible to the VHH's hydrophobic pocket. This likely explains why M2e$\mathrm{VHH}-23 \mathrm{~m}$ fails to bind to the tested avian and swine M2e peptide variants. In contrast to Ile11, M2e-Trp15, which occupies the second hydrophobic pocket of the $\mathrm{VHH}$, is strictly conserved in all known influenza A viruses. M2e Ala-scan analysis revealed that next to Ile11 and Trp15 also substitution of Val7 or Glu14 considerably impairs binding of M2e-VHH-23m. M2eVal7 is strictly conserved in all influenza A viruses and M2eGlu14 is highly conserved in human influenza A viruses. Since M2eVal7, -Ile11, -Glu14, and -Trp15 are highly conserved in all H3N2 influenza A strains, M2e-VHH-23m might have the potential to recognize the vast majority of these strains. The M2e Nterminus (SLLTEVET) is highly conserved among all influenza A viruses and is recognized by some conventional monoclonal antibodies such as MAb 148 and TCN-032. Despite employing various panning strategies using avian and swine M2e variants, we could not yet isolate a $\mathrm{VHH}$ that specifically binds the strictly conserved region in the M2e N-terminus.

Earlier we reported the crystal structures of M2e in complex with the Fab fragment of two different mouse monoclonal antibodies (MAb 65 and MAb 148) that recognize partially overlapping epitopes of $\mathrm{M} 2 \mathrm{e}(50,58)$. In these two crystal structures, M2e adopted two different conformations. The epitopes of the MAb 65 and M2e-VHH-23m are highly similar: they both span the TEVETPIRNEW fragment and in both M2eIle11 and -Trp15 are important for binding. Nevertheless, the conformation of the TEVETPIRNEW part of M2e in complex with $\mathrm{M} 2 \mathrm{e}-\mathrm{VHH}-23 \mathrm{~m}$ is very different from that in complex with the MAb 65 (Figure S3). This indicates that M2e indeed has little intrinsic structure and can adopt multiple conformations dependent on the bound antibody. This flexible nature of the M2e peptide could explain why it appears to be difficult to isolate a $\mathrm{VHH}$ that recognizes the $\mathrm{N}$-terminal part of M2e. Moreover, due to the absence of the light chain, VHHs typically bind to concave epitopes rather than to convex or protruding peptide termini (59, 60). Nevertheless a few VHHs directed against linear peptides have been described $(61,62)$. De Genst et al. reported on a VHH that binds to the C-terminus of the intrinsically disordered asynuclein protein with nanomolar range affinity (61). The crystal structure revealed that this $\mathrm{VHH}$ binds the four C-terminal amino acids of $\alpha$-synuclein by a narrow pocket formed by its CDR2 and CDR3. This suggests that it may be possible to isolate VHHs that specifically bind the highly conserved N-terminus of $\mathrm{M} 2$.

In this study, we also report the isolation of a Fc $\gamma$ RIV-specific $\mathrm{VHH}$ from a llama that had been immunized with immature mouse dendritic cells. This VHH bound to mouse Fc $\gamma$ RIV and showed no cross reactivity with the other Fc $\gamma$ Rs. To our knowledge, this is the first report of an Fc $\gamma$ RIV-specific VHH. A fibronectin scaffold protein that could specifically bind to Fc $\gamma$ RIV with high affinity has been reported (63). In addition, this scaffold protein was able to delay tumor growth in a mouse model when linked to an anti-tumor antigen-specific single-chain antibody and mouse serum albumin (to extend the half-life of the fusion construct).

The bivalent $\mathrm{VHH}$ comprising the Fc $\gamma$ RIV-specific VHH and the M2e-specific VHH, could activate the mouse Fc $\gamma$ RIV in the presence of influenza A virus infected cells. Specifically targeting only Fc $\gamma$ RIV might be an advantage over conventional antibodies since the activation of the inhibitory Fc $\gamma$ RIIb receptor, which dampens the immune cell activation, is circumvented this way. In this context, other strategies such as site-directed mutagenesis, bispecific antibody formats and glycan engineering have been explored to try to increase $\mathrm{Fc}$ binding to activating receptors and decrease the interaction with the inhibitory receptor Fc $\gamma$ RIIb (64-67). For example, afucosylated antibodies against RSV, Ebola virus and HIV with enhanced Fc $\gamma \mathrm{R}$ binding showed enhanced efficacy in rodent models (67-69).

When administered $4 \mathrm{~h}$ before and $24 \mathrm{~h}$ after infection, the bispecific Fc $\gamma$ RIV VHH-M2e VHH construct protected wildtype but not $F c \gamma R I V^{-/-}$mice against an otherwise lethal influenza A virus challenge. It is well documented that protection by M2e-specifc antibodies is Fc $\gamma \mathrm{R}$ mediated (6-9). We recently reported that wild type mice treated with an M2e-specific IgG2a showed significantly less body weight loss after infection compared with Fc $\gamma$ RIV-/- mice, suggesting that Fc $\gamma$ RIV could contribute to protection by M2e-specific IgG2a (13). Here we show that the selective activation of the mouse Fc $\gamma$ RIV with a bispecific $\mathrm{VHH}$ fusion that also binds to M2e is sufficient to protect mice against a potentially lethal influenza A virus challenge. Antitumor activity has been reported for bispecific $\mathrm{VHH}$ fusion constructs that consist of a $\mathrm{VHH}$ directed against the human Fc $\gamma$ RIIIa (the ortholog of the mouse Fc $\gamma$ RIV), fused to either a VHH directed against carcinoembryonic antigen (CEA) or HER2 $(70,71)$. In the context of viral infections, it has been reported that selective engagement of human Fc $\gamma$ RIIIa could 
A
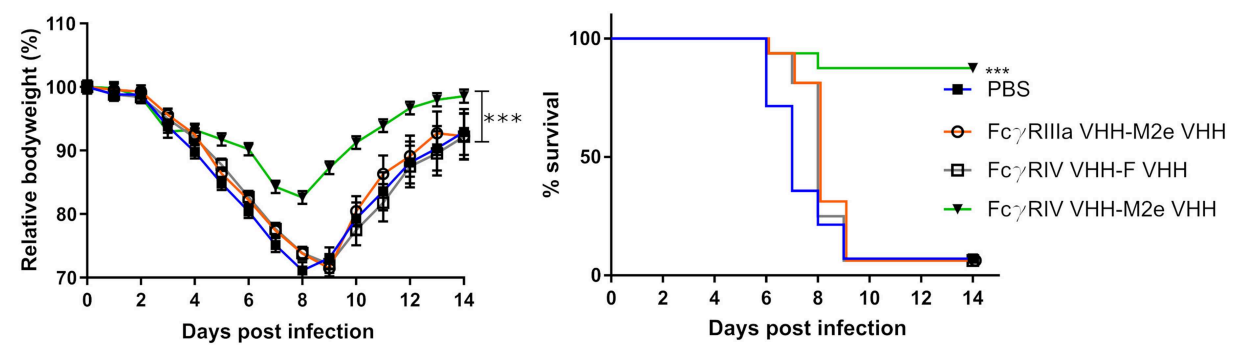

B

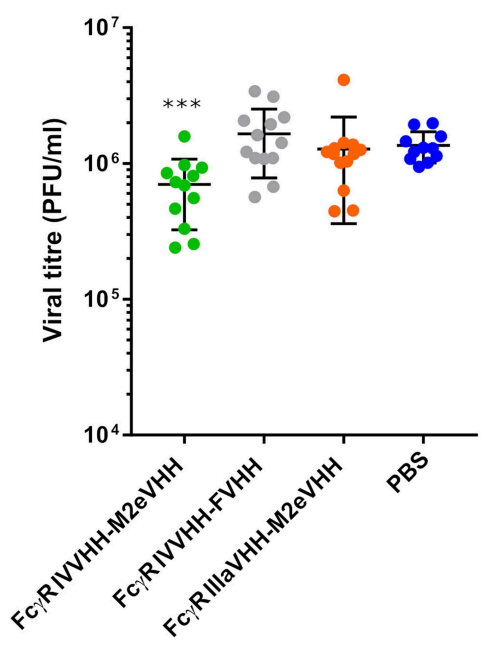

C
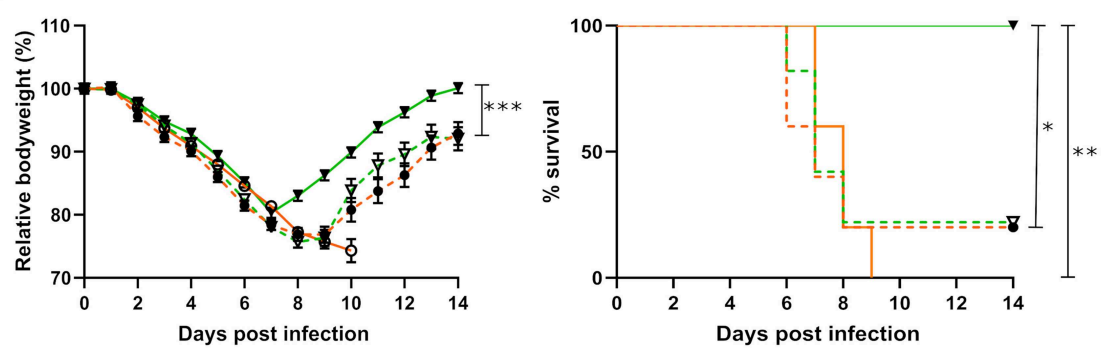

-• Fc $\gamma / \mathrm{RIIla} V \mathrm{HH}-\mathrm{M} 2 \mathrm{e} \mathrm{VHH} / \mathrm{Fc}^{-} / \mathrm{RIV}^{-/-}$

- $\boldsymbol{\nabla} \cdot \mathrm{Fc} \gamma \mathrm{RIV}$ VHH-M2e VHH/ Fc $\gamma \mathrm{RIV}^{-/-}$

- Fc $\gamma$ RIIIla VHH-M2e VHH/ WT

$\rightarrow \mathrm{Fc} \gamma / \mathrm{RIV} V \mathrm{HH}-\mathrm{M} 2 \mathrm{e}$ VHH/WT

FIGURE 7 | Bispecific fusion construct of a FcyRIV- and M2e-specific VHH protects mice against a potentially lethal influenza A virus infection. (A) Groups of 16 (bispecific VHHs) or 14 (PBS) BALB/c mice were intranasally treated with $50 \mu \mathrm{g}$ of the bispecific VHHs or PBS $4 \mathrm{~h}$ before and $24 \mathrm{~h}$ after challenge with $2 \times \mathrm{LD}_{50}$ of AX47 (H3N2) influenza virus. Body weight change (left) and survival (right) were monitored for 14 days. The mean relative changes in body weight together with their standard errors, are represented. The difference in body weight loss between Fc $\gamma \mathrm{RIV} \mathrm{VHH-M2e} \mathrm{VHH} \mathrm{and} \mathrm{the} \mathrm{negative-control} \mathrm{groups} \mathrm{was} \mathrm{statistically} \mathrm{significant} \mathrm{(* \star \star} P$ $<0.001$, REML variance components analysis). The survival rate of the group receiving Fc $\gamma \mathrm{RIV}$ VHH-M2e VHH was significantly different from Fc $\gamma$ RIV VHH-F VHH control treatment group ${ }^{\star \star \star} p<0.001$, Log-rank test). (B) To determine the effect on the viral load in the lungs, groups of 13 (bispecific VHHs) or 11 (PBS) BALB/C mice received $50 \mu \mathrm{g}$ of the bispecific VHHs or PBS $4 \mathrm{~h}$ before and $24 \mathrm{~h}$ after viral challenge with $2 \times L D_{50}$ of $A \times 47$ (H3N2) influenza virus. On day 6 after infection, the lungs were harvested and the viral titer was determined by plaque assay. The viral titer of mice Fc $\gamma \mathrm{RIV}$ VHH-M2e VHH was significantly different compared to mice that received the FC $\gamma$ RIV VHH-F VHH control treatment ( ${ }^{\star \star *} P<0.001$, unpaired $t$-test). (C) Groups of 5 wild-type and $F_{C} \gamma R / V^{-/-}$C57BL/6 mice (male and female mice) were treated with $50 \mu \mathrm{g}$ of the bispecific VHHs $4 \mathrm{~h}$ before and $24 \mathrm{~h}$ after viral challenge with $2 \times L D_{50}$ of $A / X 47$ (H3N2) influenza virus and body weight (left) and survival (right) were monitored. In the left-hand graph, data points represent means and error bars represent the standard errors of the means. Body weight changes between Fc $\gamma \mathrm{RIV}$ VHH-M2e VHH treated wild-type and Fc $\gamma \mathrm{RIV}^{-1-}$ mice were significantly different ( ${ }^{\star \star \star} P<0.001$, REML variance components analysis). The survival

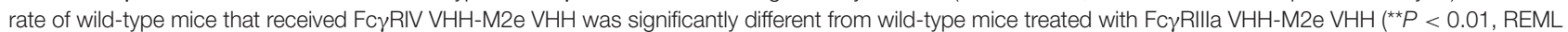
variance components analysis) and Fc $\gamma \mathrm{RIV}^{-/-}$mice treated with Fc $\gamma \mathrm{RIV}$ VHH-M2e VHH and Fc $\gamma \mathrm{RIIla}$ VHH-M2e VHH ( ${ }^{\star} P<0.05$, REML variance components analysis). Data in $\mathbf{( A , B )}$ are pooled from 2 independent experiments. 
mediate killing of HIV infected target cells by NK cells $(72,73)$. It remains to be investigated whether exchanging the mouse Fc $\gamma$ RIV specific VHH by a human Fc $\gamma$ RIIIa specific VHH in the bispecific fusion construct described here, would be able to protect against influenza $A$ virus infection in the context of a human Fc $\gamma$ R repertoire. Moreover, the M2e-specific VHH could be exchanged by a $\mathrm{VHH}$ direct against another (conserved) viral target antigen such as the hemagglutinin stalk domain, since Fc $\gamma$ Rs also seem to play an important role in the protection mediated by anti-stalk antibodies $(74,75)$.

In summary, we have demonstrated that an intranasally administered, bi-specific VHH fusion construct that selectively binds to and activates Fc $\gamma$ RIV with one moiety and M2e as present on infected target cells can protect against influenza A virus challenge. However, the treated mice still showed substantial bodyweight loss following challenge whereas intranasal administration of a M2e-specific IgG2a monoclonal antibody largely controlled the morbidity following challenge of the mice (unpublished result). In future studies one could try to optimize the $\mathrm{Fc} \gamma$ Receptor engaging $\mathrm{VHH}$-fusions by extending their lung retention, and further increasing the affinity for both the viral target and the specific Fc $\gamma$ R. Finally, when humanized, formatted M2e-specific VHHs might provide a new treatment option in the battle against influenza $A$ virus infections. This approach could also be of interest for other viral infections. Such VHHs might be especially well suited to prevent or treat respiratory infections because VHHs can be delivered directly to the site of infection as inhaled biotherapeutics by nebulization (27).

\section{DATA AVAILABILITY STATEMENT}

All datasets generated for this study are included in the article/Supplementary Material, and will also be made available by the authors, without undue reservation, to any qualified researcher.

\section{ETHICS STATEMENT}

All mouse experiments complied with national (Belgian Law 14/08/1986 and 22/12/20333, Belgian Royal Decree 06/04/2010)

\section{REFERENCES}

1. Paules CI, Fauci AS. Influenza vaccines: good, but we can do better. J Infect Dis. (2019) 219:S1-4. doi: 10.1093/infdis/jiy633

2. Koszalka P, Tilmanis D, Roe M, Vijaykrishna D, Hurt AC. Baloxavir marboxil susceptibility of influenza viruses from the Asia-Pacific, 2012-2018. Antiviral Res. (2019) 164:91-6. doi: 10.1016/j.antiviral.2019.02.007

3. Lee $\mathrm{N}$, Hurt AC. Neuraminidase inhibitor resistance in influenza: a clinical perspective. Curr Opin Infect Dis. (2018) 31:520-6. doi: 10.1097/QCO.0000000000000498

4. Saelens X. The role of M2e in the development of universal influenza vaccines. J Infect Dis. (2019) 219:S68-74. doi: 10.1093/infdis/jiz003

5. Ito T, Gorman OT, Kawaoka Y, Bean WJ, Webster RG. Evolutionary analysis of the influenza A virus M gene with comparison of the M1 and M2 proteins. J Virol. (1991) 65:5491-8. and European legislation (EU Directives 2010/63/EU and 86/609EEG) on animal regulations. All experiments were approved by and performed according to the guidelines of the animal ethical committee of Ghent University (permit number LA1400091, ethical applications EC2017-66 and EC2018-12).

\section{AUTHOR CONTRIBUTIONS}

$\mathrm{DD}, \mathrm{BS}$, and $\mathrm{XS}$ planned the study. $\mathrm{DD}, \mathrm{KH}, \mathrm{IV}, \mathrm{WN}$, $\mathrm{LV}, \mathrm{MB}, \mathrm{SC}$, and $\mathrm{BS}$ performed the research. DD, BS, IV, and XS wrote the manuscript with contributions from $\mathrm{KH}$, $\mathrm{WN}, \mathrm{HR}$, and $\mathrm{HH}$. All authors reviewed the manuscript before submission.

\section{FUNDING}

DD was supported by an IWT-SB fellowship (B/14438/57) and VIB dotation to the group of Xavier Saelens. BS was a postdoctoral assistant and LV was a junior assistant at the Department for Biomedical Molecular Biology at Ghent University and was also supported by FWO-EOS project Vir-EOS. This research was also supported by research project BOF17-GOA-018 from Ghent University, and FWO-Vlaanderen research projects G0B1917N and G043515N.

\section{ACKNOWLEDGMENTS}

We thank the VIB Nanobody Core facility for the llama immunizations and preparation of the $\mathrm{VHH}$ phage libraries. We also thank Marnik Vuylsteke for performing the statistical analysis and Geert Raes for providing the phage library of a llama immunized with immature mouse dendritic cells. We thank the beamline scientists at the i03 beamline of the Diamond Light Source synchrotron facility.

\section{SUPPLEMENTARY MATERIAL}

The Supplementary Material for this article can be found online at: https://www.frontiersin.org/articles/10.3389/fimmu. 2019.02920/full\#supplementary-material

6. Neirynck S, Deroo T, Saelens X, Vanlandschoot P, Jou WM, Fiers W. A universal influenza A vaccine based on the extracellular domain of the M2 protein. Nat Med. (1999) 5:1157-63. doi: 10.1038/13484

7. Fan J, Liang X, Horton MS, Perry HC, Citron MP, Heidecker, GJ, et al. Preclinical study of influenza virus A M2 peptide conjugate vaccines in mice, ferrets, and rhesus monkeys. Vaccine. (2004) 22:2993-3003. doi: 10.1016/j.vaccine.2004.02.021

8. Turley CB, Rupp RE, Johnson C, Taylor DN, Wolfson J, Tussey L, et al. Safety and immunogenicity of a recombinant M2e-flagellin influenza vaccine (STF2.4xM2e) in healthy adults. Vaccine. (2011) 29:5145-52. doi: 10.1016/j.vaccine.2011.05.041

9. Slepushkin VA, Katz JM, Black RA, Gamble WC, Rota PA, Cox NJ. Protection of mice against influenza A virus challenge by vaccination with baculovirus-expressed M2 protein. Vaccine. (1995) 13:1399-402. doi: 10.1016/0264-410X(95)92777-Y 
10. Ramos EL, Mitcham JL, Koller TD, Bonavia A, Usner DW, Balaratnam $\mathrm{G}$, et al. Efficacy and safety of treatment with an anti-m2e monoclonal antibody in experimental human influenza. J Infect Dis. (2015) 211:1038-44. doi: 10.1093/infdis/jiu539

11. Pendzialek J, Roose K, Smet A, Schepens B, Kufer P, Raum T, et al. Bispecific T cell engaging antibody constructs targeting a universally conserved part of the viral M2 ectodomain cure and prevent influenza A virus infection. Antiviral Res. (2017) 141:155-64. doi: 10.1016/j.antiviral.2017.02.016

12. El Bakkouri K, Descamps F, De Filette M, Smet A, Festjens E, Birkett A, et al. Universal vaccine based on ectodomain of matrix protein 2 of influenza A: Fc receptors and alveolar macrophages mediate protection. J Immunol. (2011) 186:1022-31. doi: 10.4049/jimmunol.0902147

13. Van den Hoecke S, Ehrhardt K, Kolpe A, El Bakkouri K, Deng L, Grootaert $\mathrm{H}$, et al. Hierarchical and redundant roles of activating $\mathrm{Fc} \gamma \mathrm{Rs}$ in protection against influenza disease by M2e-specific IgG1 and IgG2a antibodies. J Virol. (2017) 91:1-13. doi: 10.1128/JVI.02500-16

14. Song A, Myojo K, Laudenslager J, Harada D, Miura T, Suzuki K, et al. Evaluation of a fully human monoclonal antibody against multiple influenza A viral strains in mice and a pandemic $\mathrm{H} 1 \mathrm{~N} 1$ strain in nonhuman primates. Antiviral Res. (2014) 111:60-8. doi: 10.1016/j.antiviral.2014.08.016

15. Guilliams M, Bruhns P, Saeys Y, Hammad H, Lambrecht BN. The function of Fc $\gamma$ receptors in dendritic cells and macrophages. Nat Rev Immunol. (2014) 14:94-108. doi: $10.1038 /$ nri3582

16. Bruhns P. Properties of mouse and human IgG receptors and their contribution to disease models. Blood. (2012) 119:5640-9. doi: 10.1182/blood-2012-01-380121

17. Ra C, Jouvin MH, Blank U, Kinet JP. A macrophage Fc gamma receptor and the mast cell receptor for IgE share an identical subunit. Nature. (1989) 341:752-4. doi: 10.1038/341752a0

18. Daëron M, Latour S, Malbec O, Espinosa E, Pina P, Pasmans S, Fridman WH. The same tyrosine-based inhibition motif, in the intracytoplasmic domain of Fc gamma RIIB, regulates negatively BCR-, TCR-, and FcR-dependent cell activation. Immunity. (1995) 3:635-46. doi: 10.1016/1074-7613(95)90134-5

19. Cambier JC. New nomenclature for the Reth motif (or ARH1/TAM/ARAM/YXXL). Immunol Today. (1995) 16:110. doi: 10.1016/0167-5699(95)80105-7

20. Nimmerjahn F, Bruhns P, Horiuchi K, Ravetch JV. FcgammaRIV: a novel FcR with distinct IgG subclass specificity. Immunity. (2005) 23:41-51. doi: 10.1016/j.immuni.2005.05.010

21. Hamers-Casterman C, Atarhouch T, Muyldermans S, Robinson G, Hamers C, Songa EB, et al. Naturally occurring antibodies devoid of light chains. Nature. (1993) 363:446-8. doi: 10.1038/363446a0

22. $\mathrm{Wu} \mathrm{Y}$, Jiang $\mathrm{S}$, Ying $\mathrm{T}$. Single-domain antibodies as therapeutics against human viral diseases. Front Immunol. (2017) 8:1802. doi: 10.3389/fimmu.2017.01802

23. De Vlieger D, Ballegeer M, Rossey I, Schepens B, Saelens X. Single-domain antibodies and their formatting to combat viral infections. Antibodies. (2019) 8:1. doi: 10.3390/antib8010001

24. A Multicentre Study in Otherwise Healthy Infants and Toddlers Hospitalised For and Diagnosed With RSV Lower Respiratory Tract Infection to Evaluate the Safety, Tolerability, and Clinical Activity of ALX-0171 - Full Text View - ClinicalTrials.gov. Available online at: https://clinicaltrials.gov/ct2/show/ NCT02309320 (accessed May 17, 2019).

25. van der Linden RH, Frenken LG, de Geus B, Harmsen MM, Ruuls RC, Stok W, et al. Comparison of physical chemical properties of llama VHH antibody fragments and mouse monoclonal antibodies. Biochim Biophys Acta. (1999) 1431:37-46. doi: 10.1016/S0167-4838(99)00030-8

26. Dumoulin M, Conrath K, Van Meirhaeghe A, Meersman F, Heremans K, Frenken LGJ, et al. Single-domain antibody fragments with high conformational stability. Protein Sci. (2002) 11:500-15. doi: 10.1110/ps. 34602

27. Van Heeke G, Allosery K, De Brabandere V, De Smedt T, Detalle L, de Fougerolles A. Nanobodies $($ ) as inhaled biotherapeutics for lung diseases. Pharmacol Ther. (2017) 169:47-56. doi: 10.1016/j.pharmthera.2016. 06.012

28. De Filette M, Martens W, Roose K, Deroo T, Vervalle F, Bentahir M, et al. An influenza A vaccine based on tetrameric ectodomain of matrix protein 2. J Biol Chem. (2008) 283:11382-7. doi: 10.1074/jbc.M800650200
29. Desmedt M, Rottiers P, Dooms H, Fiers W, Grooten J. Macrophages induce cellular immunity by activating Th1 cell responses and suppressing Th2 cell responses. J Immunol. (1998) 160:5300-8.

30. Corrales-Aguilar E, Trilling M, Reinhard H, Mercé-Maldonado E, Widera $\mathrm{M}$, Schaal $\mathrm{H}$, et al. A novel assay for detecting virus-specific antibodies triggering activation of Fc $\gamma$ receptors. J Immunol Methods. (2013) 387:21-35. doi: $10.1016 /$ j.jim.2012.09.006

31. Corrales-Aguilar E, Trilling M, Hunold K, Fiedler M, Le VTK, Reinhard $\mathrm{H}$, et al. Human cytomegalovirus $\mathrm{Fc} \gamma$ binding proteins gp34 and gp68 antagonize Fc $\gamma$ receptors I, II and III. PLoS Pathog. (2014) 10:e1004131. doi: 10.1371/journal.ppat.1004131

32. Deschacht N, Groeve KD, Vincke C, Raes G, Baetselier PD, Muyldermans S. A novel promiscuous class of camelid single-domain antibody contributes to the antigen-binding repertoire. J Immunol. (2010) 184:5696-704. doi: 10.4049/jimmunol.0903722

33. Schoonooghe S, Kaigorodov V, Zawisza M, Dumolyn C, Haustraete J, Grooten J, et al. Efficient production of human bivalent and trivalent antiMUC1 Fab-scFv antibodies in Pichia pastoris. BMC Biotechnol. (2009) 9:70. doi: 10.1186/1472-6750-9-70

34. Lin-Cereghino J, Wong WW, Xiong S, Giang W, Luong LT, Vu J, et al. Condensed protocol for competent cell preparation and transformation of the methylotrophic yeast Pichia pastoris. BioTechniques. (2005) 38:44-8. doi: 10.2144/05381BM04

35. McCoy AJ, Grosse-Kunstleve RW, Adams PD, Winn MD, Storoni LC, Read RJ. Phaser crystallographic software. J Appl Crystallogr. (2007) 40:658-74. doi: 10.1107/S0021889807021206

36. Vagin A, Teplyakov A. Molecular replacement with MOLREP. Acta Crystallogr D Biol Crystallogr. (2010) 66:22-5. doi: 10.1107/S0907444909042589

37. Adams PD, Afonine PV, Bunkóczi G, Chen VB, Davis IW, Echols N, et al. PHENIX: a comprehensive Python-based system for macromolecular structure solution. Acta Crystallogr D Biol Crystallogr. (2010) 66:213-21. doi: 10.1107/S0907444909052925

38. Emsley P, Cowtan K. Coot: model-building tools for molecular graphics. Acta Crystallogr D Biol Crystallogr. (2004) 60:2126-32. doi: 10.1107/S0907444904019158

39. Afonine PV, Grosse-Kunstleve RW, Echols N, Headd JJ, Moriarty NW, Mustyakimov $\mathrm{M}$, et al. Towards automated crystallographic structure refinement with phenix.refine. Acta Crystallogr D Biol Crystallogr. (2012) 68:352-67. doi: 10.1107/S0907444912001308

40. Murshudov GN, Vagin AA, Dodson EJ. Refinement of macromolecular structures by the maximum-likelihood method. Acta Crystallogr D Biol Crystallogr. (1997) 53:240-55. doi: 10.1107/S0907444996012255

41. Guex N, Peitsch MC. SWISS-MODEL and the Swiss-PdbViewer: an environment for comparative protein modeling. Electrophoresis. (1997) 18:2714-23. doi: 10.1002/elps.1150181505

42. Hanwell MD, Curtis DE, Lonie DC, Vandermeersch T, Zurek E, Hutchison GR. Avogadro: an advanced semantic chemical editor, visualization, and analysis platform. J Cheminform. (2012) 4:17. doi: 10.1186/1758-2946-4-17

43. Morris GM, Huey R, Lindstrom W, Sanner MF, Belew RK, Goodsell DS, et al. AutoDock4 and AutoDockTools4: automated docking with selective receptor flexibility. J Comput Chem. (2009) 30:2785-91. doi: 10.1002/jcc.21256

44. Trott O, Olson AJ. AutoDock vina: improving the speed and accuracy of docking with a new scoring function, efficient optimization and multithreading. J Comput Chem. (2010) 31:455-61. doi: 10.1002/jcc.21334

45. Koes DR, Baumgartner MP, Camacho CJ. Lessons learned in empirical scoring with smina from the CSAR 2011 benchmarking exercise. J Chem Inf Model. (2013) 53:1893-904. doi: 10.1021/ci300604z

46. PyMOL | pymol.org. Available online at: https://pymol.org/2/ (accessed July 3 , 2019).

47. Sarrion-Perdigones A, Vazquez-Vilar M, Palací J, Castelijns B, Forment J, Ziarsolo P, et al. GoldenBraid 2.0: a comprehensive DNA assembly framework for plant synthetic biology. Plant Physiol. (2013) 162:1618-31. doi: 10.1104/pp.113.217661

48. Behar G, Sibéril S, Groulet A, Chames P, Pugnière M, Boix C, et al Isolation and characterization of anti-FcgammaRIII (CD16) llama singledomain antibodies that activate natural killer cells. Protein Eng Des Sel. (2008) 21:1-10. doi: 10.1093/protein/gzm064 
49. Nimmerjahn F, Lux A, Albert H, Woigk M, Lehmann C, Dudziak D, et al. Fc $\gamma$ RIV deletion reveals its central role for IgG2a and IgG2b activity in vivo. Proc Natl Acad Sci USA. (2010) 107:19396-401. doi: 10.1073/pnas.1014515107

50. Cho KJ, Schepens B, Seok JH, Kim S, Roose K, Lee J-H, et al. Structure of the extracellular domain of matrix protein 2 of influenza A virus in complex with a protective monoclonal antibody. J Virol. (2015) 89:3700-11. doi: 10.1128/JVI.02576-14

51. Kunz P, Zinner K, Mücke N, Bartoschik T, Muyldermans S, Hoheisel JD. The structural basis of nanobody unfolding reversibility and thermoresistance. Sci Rep. (2018) 8:7934. doi: 10.1038/s41598-018-26338-z

52. Rossey I, Gilman MSA, Kabeche SC, Sedeyn K, Wrapp D, Kanekiyo M, et al. Potent single-domain antibodies that arrest respiratory syncytial virus fusion protein in its prefusion state. Nat Commun. (2017) 8:14158. doi: $10.1038 /$ ncomms 14158

53. Liu Y, Eisenberg D. 3D domain swapping: as domains continue to swap. Protein Sci. (2002) 11:1285-99. doi: 10.1110/ps.0201402

54. Zebedee SL, Lamb RA. Influenza A virus M2 protein: monoclonal antibody restriction of virus growth and detection of M2 in virions. J Virol. (1988) 62:2762-72.

55. Kolpe A, Schepens B, Ye L, Staeheli P, Saelens X. Passively transferred M2especific monoclonal antibody reduces influenza A virus transmission in mice. Antiviral Res. (2018) 158:244-54. doi: 10.1016/j.antiviral.2018.08.017

56. Kolpe A, Arista-Romero M, Schepens B, Pujals S, Saelens X, Albertazzi L. Super-resolution microscopy reveals significant impact of M2e-specific monoclonal antibodies on influenza A virus filament formation at the host cell surface. Sci Rep. (2019) 9:4450. doi: 10.1038/s41598-019-41023-5

57. Wei G, Meng W, Guo H, Pan W, Liu J, Peng T, et al. Potent neutralization of influenza A virus by a single-domain antibody blocking M2 ion channel protein. PLoS ONE. (2011) 6:e28309. doi: 10.1371/journal.pone.0028309

58. Cho KJ, Schepens B, Moonens K, Deng L, Fiers W, Remaut H, et al. Crystal structure of the conserved amino terminus of the extracellular domain of matrix protein 2 of influenza A virus gripped by an antibody. J Virol. (2015) 90:611-5. doi: 10.1128/JVI.02105-15

59. Pírez-Schirmer M, Rossotti M, Badagian N, Leizagoyen C, Brena BM, González-Sapienza G. Comparison of three antihapten VHH selection strategies for the development of highly sensitive immunoassays for microcystins. Anal Chem. (2017) 89:6800-6. doi: 10.1021/acs.analchem.7b01221

60. De Genst E, Silence K, Decanniere K, Conrath K, Loris R, Kinne J, et al. Molecular basis for the preferential cleft recognition by dromedary heavy-chain antibodies. Proc Natl Acad Sci USA. (2006) 103:4586-91. doi: 10.1073/pnas.0505379103

61. De Genst EJ, Guilliams T, Wellens J, O’Day EM, Waudby CA, Meehan $\mathrm{S}$, et al. Structure and properties of a complex of $\alpha$-synuclein and a single-domain camelid antibody. J Mol Biol. (2010) 402:326-43. doi: 10.1016/j.jmb.2010.07.001

62. Braun MB, Traenkle B, Koch PA, Emele F, Weiss F, Poetz O, et al. Peptides in headlock - a novel high-affinity and versatile peptide-binding nanobody for proteomics and microscopy. Sci Rep. (2016) 6:19211. doi: 10.1038/srep19211

63. Chen TF, Li KK, Zhu EF, Opel CF, Kauke MJ, Kim H, et al. Artificial anti-tumor opsonizing proteins with fibronectin scaffolds engineered for specificity to each of the murine Fc $\gamma$ R types. J Mol Biol. (2018) 430:1786-98. doi: 10.1016/j.jmb.2018.04.021

64. Shields RL, Namenuk AK, Hong K, Meng YG, Rae J, Briggs J, et al. High resolution mapping of the binding site on human IgG1 for Fc gamma RI, Fc gamma RII, Fc gamma RIII, and FcRn and design of IgG1 variants with improved binding to the Fc gamma R. J Biol Chem. (2001) 276:6591-604. doi: 10.1074/jbc.M009483200
65. Mori K, Iida S, Yamane-Ohnuki N, Kanda Y, Kuni-Kamochi R, Nakano R, et al. Non-fucosylated therapeutic antibodies: the next generation of therapeutic antibodies. Cytotechnology. (2007) 55:109-14. doi: 10.1007/s10616-007-9103-2

66. Müller D, Karle A, Meissburger B, Höfig I, Stork R, Kontermann RE. Improved pharmacokinetics of recombinant bispecific antibody molecules by fusion to human serum albumin. J Biol Chem. (2007) 282:12650-60. doi: 10.1074/jbc.M700820200

67. Hiatt A, Bohorova N, Bohorov O, Goodman C, Kim D, Pauly MH, et al Glycan variants of a respiratory syncytial virus antibody with enhanced effector function and in vivo efficacy. Proc Natl Acad Sci USA. (2014) 111:5992-7. doi: 10.1073/pnas.1402458111

68. Bardhi A, Wu Y, Chen W, Li W, Zhu Z, Zheng JH, et al. Potent in vivo NK cellmediated elimination of HIV-1-infected cells mobilized by a gp120-bispecific and hexavalent broadly neutralizing fusion protein. J Virol. (2017) 91:1-19. doi: 10.1128/JVI.00937-17

69. Zeitlin L, Pettitt J, Scully C, Bohorova N, Kim D, Pauly M, et al. Enhanced potency of a fucose-free monoclonal antibody being developed as an Ebola virus immunoprotectant. Proc Natl Acad Sci USA. (2011) 108:20690-4. doi: $10.1073 /$ pnas. 1108360108

70. Rozan C, Cornillon A, Pétiard C, Chartier M, Behar G, Boix C, et al. Single-domain antibody-based and linker-free bispecific antibodies targeting Fc $\gamma$ RIII induce potent antitumor activity without recruiting regulatory $\mathrm{T}$ cells. Mol Cancer Ther. (2013) 12:1481-91. doi: 10.1158/1535-7163.MCT-121012

71. Turini M, Chames P, Bruhns P, Baty D, Kerfelec B. A Fc $\gamma$ RIIIengaging bispecific antibody expands the range of HER2-expressing breast tumors eligible to antibody therapy. Oncotarget. (2014) 5:5304-19. doi: 10.18632/oncotarget.2093

72. Li W, Wu Y, Kong D, Yang H, Wang Y, Shao J, et al. One-domain CD4 fused to human anti-CD16 antibody domain mediates effective killing of HIV-1-infected cells. Sci Rep. (2017) 7:9130. doi: 10.1038/s41598-017-0 7966-3

73. Gleason MK, Verneris MR, Todhunter DA, Zhang B, McCullar V, Zhou $\mathrm{SX}$, et al. Bispecific and trispecific killer cell engagers directly activate human NK cells through CD16 signaling and induce cytotoxicity and cytokine production. Mol Cancer Ther. (2012) 11:2674-84. doi: 10.1158/1535-7163.MCT-12-0692

74. DiLillo DJ, Tan GS, Palese P, Ravetch JV. Broadly neutralizing hemagglutinin stalk-specific antibodies require $\mathrm{Fc} \gamma \mathrm{R}$ interactions for protection against influenza virus in vivo. Nat Med. (2014) 20:143-51. doi: 10.1038/ nm.3443

75. Thulin NK, Wang TT. The role of Fc gamma receptors in broad protection against influenza viruses. Vaccines (Basel). (2018) 6:36. doi: $10.3390 /$ vaccines6030036

Conflict of Interest: The authors declare that the research was conducted in the absence of any commercial or financial relationships that could be construed as a potential conflict of interest.

Copyright (c) 2019 De Vlieger, Hoffmann, Van Molle, Nerinckx, Van Hoecke, Ballegeer, Creytens, Remaut, Hengel, Schepens and Saelens. This is an open-access article distributed under the terms of the Creative Commons Attribution License (CC $B Y)$. The use, distribution or reproduction in other forums is permitted, provided the original author(s) and the copyright owner(s) are credited and that the original publication in this journal is cited, in accordance with accepted academic practice. No use, distribution or reproduction is permitted which does not comply with these terms. 